\title{
Constraining the Likely Technological Niches of Late Middle Pleistocene Hominins with Homo naledi as Case Study
}

\author{
Gerrit L. Dusseldorp ${ }^{1,2}$ (D) Marlize Lombard ${ }^{2}$ (D)
}

Accepted: 15 December 2020 / Published online: 26 January 2021

(C) The Author(s) 2021

\begin{abstract}
We develop a framework to differentiate the technological niches of co-existing hominin species by reviewing some theoretical biases influential in thinking about techno-behaviours of extinct hominins, such as a teleological bias in discussing technological evolution. We suggest that some stone-tool classification systems underestimate technological variability, while overestimating the complexity of the behaviours most commonly represented. To model the likely technological niches of extinct populations, we combine ecological principles (i.e. competitive exclusion) with physical anthropology and the archaeological record. We test the framework by applying it to the co-existence of Homo naledi and Homo sapiens during the late Middle Pleistocene in southern Africa. Based on our analysis, we suggest that tool use was probably not an essential part of $H$. naledi's niche, but that technology occasionally provided caloric benefits. In contrast, tool use was a structural part of the $H$. sapiens way of life. We provide reasoning for our interpretation that the latter population is associated with more sophisticated reduction strategies and the development of prepared core technology. The method also has applicability to cases such as the co-existence of different toolmakers during the Earlier Stone Age (ESA) in East Africa and the co-existence of Neanderthals and H. sapiens in Eurasia.
\end{abstract}

Keywords Sympatric hominins $\cdot$ Techno-behaviours $\cdot$ Teleological bias $\cdot$ Technological niches $\cdot$ Extinct hominins $\cdot$ Caloric benefits $\cdot$ Obligatory tool use

Gerrit L. Dusseldorp

g.l.dusseldorp@arch.leidenuniv.nl

1 Faculty of Archaeology, Leiden University, Leiden, the Netherlands

2 Palaeo-research Institute, University of Johannesburg, Johannesburg, South Africa 


\section{Introduction}

Throughout the Pleistocene hominin species frequently co-existed (Wood and Boyle 2016). This poses an archaeological dilemma: As all members of the genus Homo are assumed to occupy a technologically-assisted niche, how do we tie archaeological remains to specific hominin species in situations of co-existence? To understand hominin lifeways, especially when they occur sympatrically, insight into their techno-behaviours is required (Shea 2003; Susman 1994; Tocheri et al. 2008).

With this contribution, we explore how archaeology can deal with the co-occurrence of different hominins. We first highlight theoretical positions that influence archaeological hypothesis building and may lead us to underestimate the variability exhibited in the archaeological record. We also explore the mechanisms responsible for the transmission of stone tool technology in hominins. We argue that archaeological thinking often exhibits subtle biases that are problematic. We propose that detailed ecological niche modelling, combined with anatomical information on hominin adaptations, can constrain interpretations of a specie's technological repertoires. Our main assumption is that to understand the development of technology, a focus on its adaptive role is key (Shea 2017). Although non-human primates and other animals occasionally use tools, the human niche differs from theirs as it fully depends on technology (Shea 2017), and in hunter-gatherer societies, technology pervades all aspects of life and varies from simple tools to large installations.

We illustrate our approach with a case study of the Middle Pleistocene archaeology of South Africa, where early Homo sapiens may have co-existed with Homo naledi (Berger et al. 2015; Berger et al. 2017; Dirks et al. 2017; Lombard et al. 2018). Based on its estimated age, small-brained $H$. naledi has been considered a potential producer of Middle Stone Age, prepared core technology (Berger et al. 2017). Hawks and Berger (2020) argue that the temporal and geographic overlap of $H$. naledi with that of evolving $H$. sapiens confounds current scientific thinking about niche development for the two species, claiming a largely similar niche for both. Our aim is to evaluate hypotheses on the techno-behaviours of $H$. naledi and its ecological niche using three strands of evidence: ecology, anatomy, and archaeology. Our approach constrains interpretations of the likely technological repertoire of $H$. naledi-resulting in a parsimonious, best-fit hypothesis. We contextualise this within the wider archaeological record to further specify the role of stone tools in likely $H$. naledi technobehaviours. By explicitly considering the fitness benefits of stone tool use in combination with the ecological context and the specific anatomical features of different hominins, we suggest that the archaeological record can be more productively associated with different species. We touch on other instances of co-existence such as the European Middle-to-Upper Palaeolithic transition to illustrate the wider relevance of our approach.

\section{Co-existing Hominins-Niche Differentiation}

To co-exist in a geographic area in the longer term, the ecological niches of distinct hominin groups must be differentiated. If their niches overlap significantly, one of the two species will go (locally) extinct. This principle of competitive exclusion is well- 
established (see discussion in Foley 1987). Unfortunately, the geographical and temporal extent of hominin co-existence is difficult to determine. Archaeological dating methods have been combined with Bayesian statistics to determine whether cultural entities overlap (cf. Higham et al. 2014). Such models rely on the attribution of lithic industries to specific populations (e.g. Benazzi et al. 2014; Cortés-Sánchez et al. 2019; Ruebens et al. 2015). These attributions are often contested (e.g. Bar-Yosef and Bordes 2010; Villa et al. 2018), and in many cases, taphonomic circumstances preclude a determination of authorship (Gravina et al. 2018; Gravina et al. 2005; Zilhão et al. 2006). These complicating factors led to the search for alternative approaches to investigate the extent of, for example, Neanderthal and $H$. sapiens coexistence. The principle of competitive exclusion is a suitable starting point to make sense of the archaeological record of co-existing hominins. Unless the characters are captured 'tool in hand', attribution to specific species can only be achieved if we know how the tools were used within a given hominin niche.

\section{Encephalising Trends Inferred from the Fossil Record}

Evolutionary discourse in archaeology exhibits gradualist and teleological tendencies, which influences how the fossil and lithic records are studied. The evolution of the genus Homo is generally characterised by increasing brain size across different species (Gómez-Robles et al. 2017; Potts 2011; Galway-Witham et al. 2019). Large brains are seen as integral to the human niche (Kaplan et al. 2000).

Extensive variability in both body and brain size of, for example, African $H$. erectus populations (Potts et al. 2004) have been mostly ignored. Extreme cases such as Homo floresiensis, a small-brained, small-bodied species, were initially seen as due to island biogeography (Morwood et al. 2004). More recent work, however, suggests that the species is a long-surviving relict of an early $(>1.75 \mathrm{Ma})$, as yet unknown 'out of Africa' hominin lineage (Argue et al. 2017), further complicating the question of how a late-surviving species may relate to an archaeological industry. The Middle Pleistocene age of another small-brained species, $H$. naledi (estimated brain size $465-610 \mathrm{~cm}^{3}$ ) in southern Africa also challenges standard interpretations of the fossil record (Berger et al. 2015; Dirks et al. 2017; Hawks et al. 2017). Different from island-isolated H. floresiensis, it shows that small-brained hominins co-existed with large-brained ones on the same landscape.

Brain size is an influential concept in human evolution, also used as a criterion for the inclusion of species in the genus Homo (Wood 2014). Increasing brain size is often assumed to confer greater cognitive ability (but see Lombard and Högberg 2021 for later humans). As a result, subsistence strategies, technological repertoires, and social systems are thought to become more elaborate (Foley and Gamble 2009). However, large brains also entail significant evolutionary costs, due to high energetic demands (e.g. Aiello and Key 2002; Isler and van Schaik 2009; Navarrete et al. 2011). This suggests encephalising hominins faced strong selection pressures favouring brain growth.

The very few known Middle Pleistocene African hominin fossils are usually placed within the trend of a gradual increase in brain size (Table 1). Exactly how some descendants of $H$. erectus/ergaster ultimately develop into $H$. sapiens in Africa is 


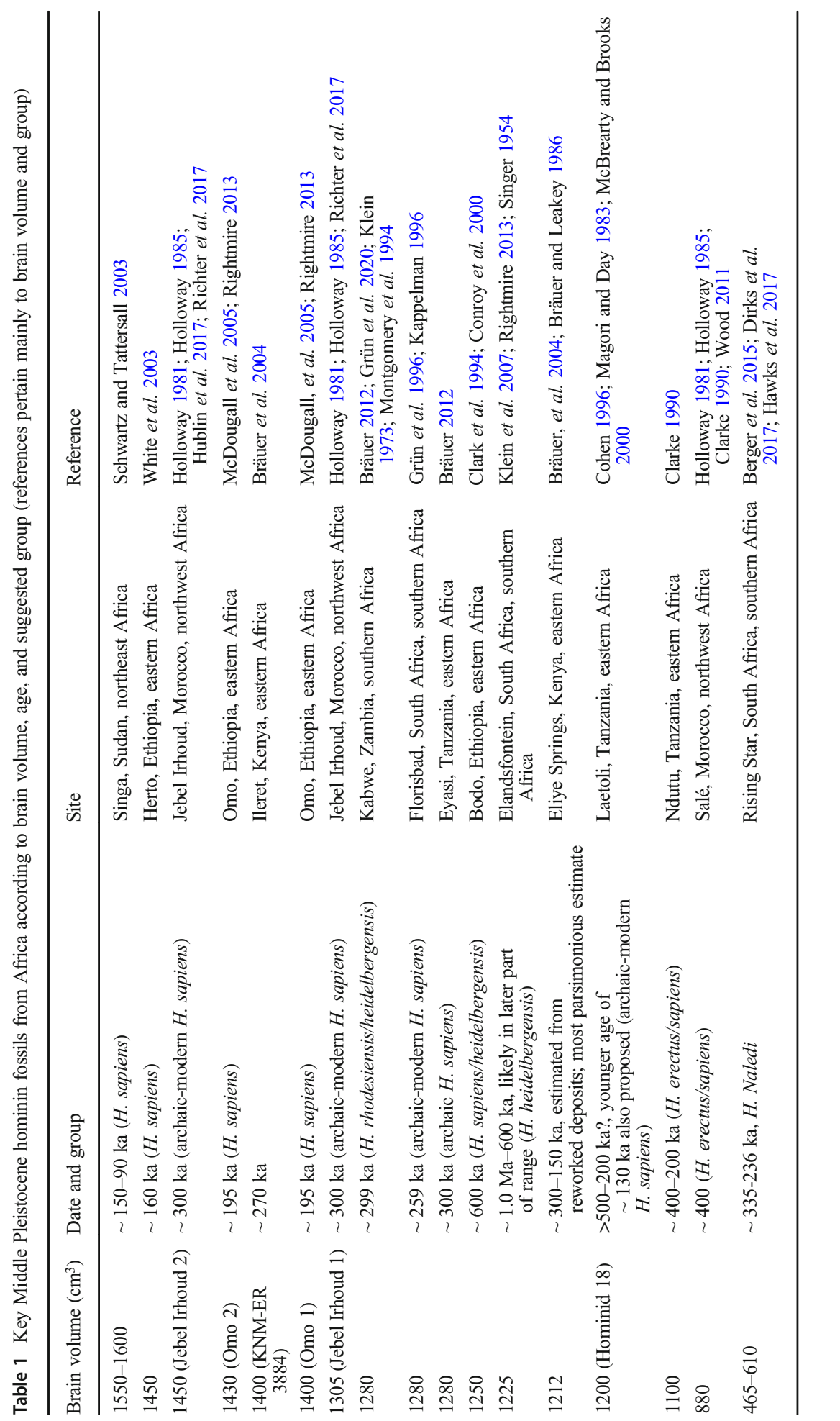


unclear. Some suggest that a group of African and European fossils can be attributed to $H$. heidelbergensis, while others group the African fossils in the separate taxon of H. rhodesiensis. It appears that distinct large-brained taxa co-existed in Africa (Hublin et al. 2017; Grün et al. 2020). This is supported by genetic indications for archaic admixture in contemporary genomes (Hammer et al. 2011). For the purposes of our study, we regard these fossils as belonging to an evolutionary lineage with a last common ancestor that lived at a more recent time than the last common ancestor of $H$. naledi and the larger-brained populations. Both early $H$. sapiens and H. heidelbergensis/rhodesiensis have been found associated with Middle Stone Age stone artefacts (Richter et al. 2017; Grün et al. 2020). The specimens of Elandsfontein, Kabwe, and Florisbad demonstrate that the encephalising lineage was present in southern Africa during the Middle Pleistocene. The age estimate of $H$. naledi implies that the encephalising lineage co-existed with a small-brained species - challenging notions of s steady temporal increase in brain size across different hominin species. This suggests the existence of up-to-now unexplored alternative solutions to the ecological problems faced by African hominins.

\section{The South African Fossil Record}

In addition to the $H$. naledi findspot, only four late Middle Pleistocene sites have yielded hominin fossils, Florisbad, Cave of Hearths, Hoedjiespunt, and Lincoln Cave at Sterkfontein (also see Berger et al. 2017; Dusseldorp et al. 2013). The Florisbad cranium belongs to one of the earliest representatives of the H. sapiens clade (Richter et al. 2017). Found in spring deposits in the Free State, it may be associated with Middle Stone Age lithic technology (Kuman et al. 1999) and combines a substantial brain size with a robust build (Rightmire 1978; Bruner and Lombard 2020) (Fig. 1).

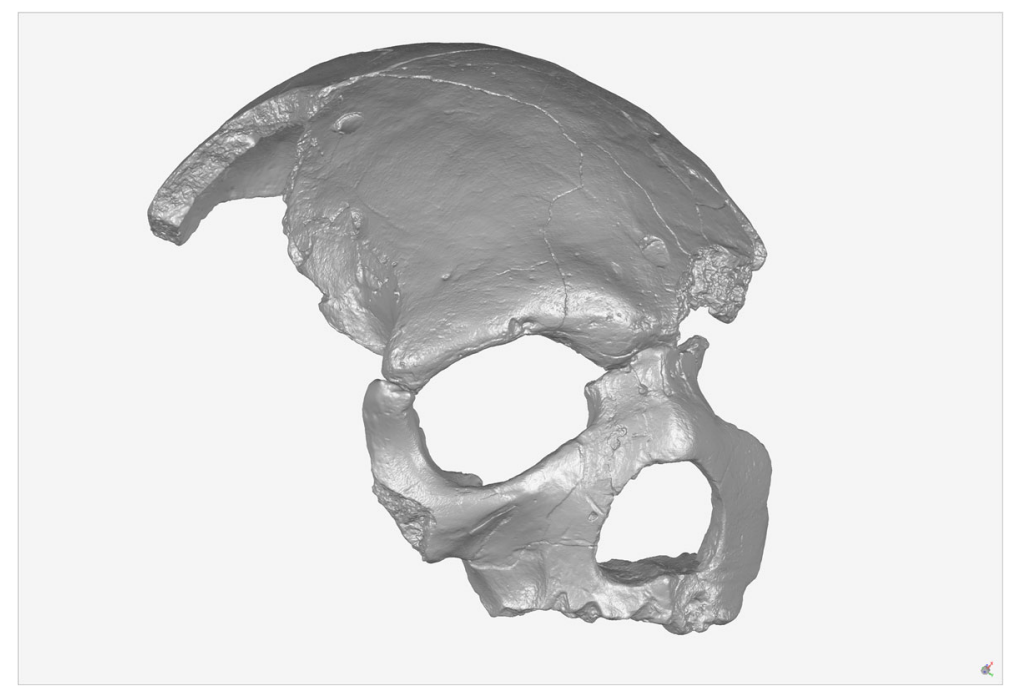

Fig. 1 3D scan on the Florisbad cranium (scan produced by I. Djakovic, reconstruction of skullcap and facial part by Matt Caruana, University of Johannesburg, image () Marlize Lombard). 
A radius and a robust jawbone with a number of teeth were found at Cave of Hearths, initially ascribed to archaic H. sapiens (Hawks et al. 2017; Tobias 1971). Dental analysis shows the teeth to be allied to $H$. heidelbergensis, and different from H. naledi (Davies et al. 2019). The mandible is associated with a late Acheulean industry; whereas the provenance of the radius is not known exactly, it has been associated with either late Acheulean or early Middle Stone Age (Tobias 1971). A large tibia from Hoedjiespunt has been attributed to $H$. heidelbergensis (Churchill et al. 2000). Its dimensions demonstrate a much larger body size than H. naledi, but no archaeological remains are associated with it (Stynder et al. 2001). At Lincoln Cave in Sterkfontein, isolated teeth and a small cranial fragment were found in Middle to Late Pleistocene deposits. However, there is evidence of post-depositional mixing, with material assigned to $H$. ergaster and archaic $H$. sapiens co-occurring with Acheulean and Middle Stone Age artefacts (Reynolds et al. 2007). Because the context of the hominin fossils was not directly dated and post-depositional mixing is attested, we omit the site from our analysis.

Despite the small amount of hominin material, the estimated age of $H$. naledi suggests that at least two very different populations existed in South Africa during the early phase of the Middle Stone Age. Both the Hoedjiespunt and the Florisbad fossils, and likely the Cave of Hearths maxilla demonstrate the presence of a large-bodied, large-brained hominin in South Africa at the same time as the diminutive $H$. naledi.

\section{Challenges for the Archaeological Study of Technological Niches}

Archaeological understanding of the adaptive significance of hominin tool use is hampered by taphonomic and epistemic factors. First, the archaeological visibility of hominin techno-behaviours is biased towards knapped stone tools. However, the ability to use other types of artefacts, either unmodified stones or organic tools may have exerted equally strong selection pressures on evolving hominins. Organic tools are widely used by contemporary hunter-gatherers and by non-human primates. Although their use was likely ubiquitous throughout hominin evolution, their archaeological visibility depends on serendipitous discoveries in rare circumstances. Yet, from such discoveries, we can document a long and varied record of organic tools from bone digging implements in South Africa at 2.3 Mya (Backwell and d'Errico 2008; Stammers et al. 2018), to in Indonesian H. erectus shell tools at $500 \mathrm{ka}$ (Joordens et al. 2015), and wooden spears $(\sim 300 \mathrm{ka})$ and digging sticks $(\sim 170 \mathrm{ka})$ used by Neanderthals (Aranguren et al. 2018; Milks et al. 2019). Taphonomy thus largely obscures a major component of hominin tool use.

Similarly, the use of unmodified stones is understudied, due to a lack of sound methodological approaches (Caruana et al. 2014). Nevertheless, it is clearly in evidence in later populations that exhibit obligatory tool use such as Neanderthals (Pop et al. 2018). The oldest knapped stone tools may date back to 3.3 Mya although the stratigraphic provenance of the published artefacts has been critiqued (Harmand et al. 2015; Lewis and Harmand 2016; Domínguez-Rodrigo and Alcalá 2017; Archer et al. 2020). In any event, it appears that knapped stone tool use was occasional until $\sim 1.7$ Mya (Shea 2017). And knapping was not practised equally by all hominin populations. 
This is illustrated by the potential 'loss' of knapped stone tool technologies by Homo erectus populations inhabiting the Far East (Joordens et al. 2015). The use of archaeologically less visible tool types likely exerted important selective pressures on hominin lifeways.

\section{Trends Inferred from the Archaeological Record}

Technology is often taken as a proxy of hominin cognition. As with developing brain size, gradualist and teleological tendencies are exhibited in the study of stone tools. Technological complexity is generally assumed to increase over time, thus progressively gaining in the lengths and numbers of nested steps involved in their manufacture. However, this assumption is poorly supported (Hoffecker and Hoffecker 2018; Vaesen and Houkes 2018). Similar to increases in brain size, increased technological complexity is assumed to take place across different species. We discuss the basic classifications of lithic technology (as the most prolific remnants of Pleistocene techno-behaviours) and examine variability that is overlooked by focussing on so-called complexity.

The assumed increasing complexity of knapped stone tool technology is reflected in Clarke's (1969) widely used classification of lithic industries. Knapping strategies are divided into five modes from basic to complex. These modes are sometimes envisaged as a sequential development, with mode 1 being replaced by mode 2 , etc. Alternative descriptions of toolmaking strategies without underlying cognitive implications have been proposed (Shea 2013, 2017). Because Clarke's modes 1-5 are in near-universal use, we use this terminology. However, we view the sequential replacement of modes as too simplistic. The utilisation of different modes of knapping is better described by time-transgressive scenarios with different modes simultaneously used (see Foley and Lahr 2003; Shea 2011, 2017; also see Shipton 2018 on trends in Acheulean biface knapping), and we use the modal terminology in this context.

Modes 1 to 3 characterise the main subdivisions of the Stone Age and Palaeolithic. The Earlier Stone Age (roughly equivalent to the Lower Palaeolithic outside of Africa) is characterised by mode 1 and mode 2 technologies. Mode 1 technology centres on knapping flakes (débitage). Unstandardised flakes are struck from cores without platform preparation. This mode is exemplified by the Oldowan Industry (Leakey 1971), but also includes later industries such as the Clactonian in Europe (MIS 11: 425-375 ka) (Wenban-Smith et al. 2006; White 2000). The initial use of mode 1 technology is associated with small-brained early Homo, such as H. habilis and potentially late Australopithecines and Paranthropus, but mode 1 was also produced later by $H$. ergaster/erectus, $H$. antecessor, and others.

Mode 2 is characterised by shaped tools (façonnage). Its central feature is the production of roughly symmetrical large cutting tools (LCTs) such as handaxes and cleavers. This mode is represented by the Acheulean complex, distributed across Africa and parts of Eurasia between $~ 1.7$ and 0.3 Mya (Lepre et al. 2011; Lycett and Gowlett 2008). In the early Acheulean, the LCTs are unstandardised and show few removals (Beyene et al. 2013; Diez-Martín et al. 2015). They become gradually more carefully shaped, showing larger numbers of flake removals, soft hammer percussion, and purposeful thinning using platform preparation (Diez-Martín et al. 2015; Stout et al. 2014). The initial use of mode 2 technology is associated with H. ergaster in Africa. 
The Middle Stone Age (roughly equivalent to the Middle Palaeolithic in Eurasia) is characterised by mode 3 technology. Mode 3, or prepared core technology, focuses on producing flakes of predetermined form from hierarchically organised cores. This technology is associated with routine platform preparation. It takes many different forms and was probably independently invented at different places across the Old World (Adler et al. 2014). The Levallois technique is most synonymous with mode 3. By $\sim 300 \mathrm{ka}$, mode 3 technology was in wide-spread use, continuing to $\sim 40-20 \mathrm{ka}$ (Barton et al. 2016; Osypiński and Osypińska 2016). The use of prepared core technology is associated with large-brained hominins such as Neanderthals, H. heidelbergensis, and H. sapiens (Adler et al. 2014).

Teleological bias is revealed when the classification of assemblages is made based on the most complex mode/s of production represented. But the time-transgressive occurrence of different modes of knapping blinds us to variability in the archaeological record. Artefacts deposited in a high-resolution stratigraphic context are only rarely available. In South Africa for example, the land surface has been stable throughout the Earlier and Middle Stone Ages, leading to the formation of many palimpsest surface collections containing artefacts of vastly different ages (Klein 2000). In many assemblages, both from the surface and excavated contexts, prepared core forms are accompanied by a host of other forms, often characterised as 'informal' (Kiberd 2006, table 3; Thompson et al. 2010, table 6).

Teleological tendencies are also apparent in the way in which chronological information and lithic classifications are used to reinforce each other. Mode 1 and mode 2 occurrences without direct dates are sometimes suggested to represent ancient occupations and prepared core occurrences in the same area are thought to reflect more recent hominin activities (e.g. Terry 2005). However, in regions with better chronostratigraphic control such as East Africa, mode 2 (bifacial) and mode 1 (irregularly flaked) assemblages continue to occur throughout the Middle Stone Age (Foley and Lahr 2003; McBrearty 2005; Shea 2011). Acheulean (mode 2) and Clactonian (mode 1) assemblages also co-occur in the United Kingdom during MIS 11 (Wenban-Smith et al. 2006; White 2000). In reverse, assemblages lacking diagnostic artefacts are sometimes assigned to an industry on the basis of radiometric dates only (e.g. Clark 1993; de la Peña 2019).

Technologies are part of a larger ecological niche, and increased complexity is not necessarily universally beneficial. Especially when different hominins co-exist, these biases leading to the underestimation of techno-cultural variability are problematic. Overlooking variability and using 'circumstantial factors', such as the age of assemblages to classify them, hamper a deeper understanding of the formation of lithic assemblages and differences in hominin niches.

\section{Computer Simulation-Teleology in Action}

Computer simulations of the potential co-existence of different hominins exemplifies the subtle but pervasive teleological bias in archaeological thinking. This analytical approach is increasingly favoured as an 'objective' tool to simulate situations of hominin co-existence and extinction. Models of reproducing hominin populations (usually $H$. sapiens and Neanderthals) are formulated, 
based on assumed characteristics. A simulation is run to calculate if, and for how long, populations will co-exist. Such simulations invariably end in Neanderthal extinction. They attempt to recreate the actual history, but do not necessarily illuminate the reasons for the known outcome, because the input generally features differences in the characteristics of the populations. An early and ground-breaking simulation, for example, modelled the life-expectancy of Neanderthals as dependent on the life-expectancy of $H$. sapiens populations (Zubrow 1989). However, this model only allowed for one-way traffic; changes in Neanderthal life expectancy could not affect that of $H$. sapiens. Such models present a foregone conclusion as one population is handicapped and will inevitably go extinct (Scherjon 2019; Vaesen et al. 2019).

In addition to demographic models, some models focus on various assumed behavioural differences between Neanderthals and $H$. sapiens, for example, trade between groups and a more explicit division of labour (Horan et al. 2005). Other models focus on assumed differences in 'culture level' or learning ability (Gilpin et al. 2016), or in caloric requirements and differences in fire use (Goldfield et al. 2018). Again, the assumed advantages of H. sapiens over Neanderthals invariably cause the demise of the latter.

Some recent models do not assume selective differences and focus on demographic processes (Kolodny and Feldman 2017). However, such models still handicap Neanderthals in subtle ways. One version stipulates that bands of each species periodically go extinct, but with continuous in-migration of $H$. sapiens groups into Neanderthal territory. This ensures $H$. sapiens never go extinct altogether in the simulation. In another version, bidirectional migration is allowed. However, the simulation stipulates that at least as many H. sapiens individuals migrate into Europe as Neanderthals move into Africa. In addition, the initial $H$. sapiens population is modelled to be larger than the Neanderthal population, again leading to the likely extinction of Neanderthals (Kolodny and Feldman 2017). Hence, Neanderthals are still modelled as handicapped in so-called neutral models (Scherjon 2019; Vaesen et al. 2019).

The assumptions of simulations are not necessarily incorrect. However, taking one outcome as virtually inevitable, and ignoring gene-flow between populations (see discussion in Lombard and Högberg 2021), is of limited value in testing hypotheses on the causes and likelihood of that outcome. This excursion illustrates the kind of gradualist, teleological thinking that dominates ideas on hominin anatomic, behavioural, and technological evolution. To move forward, we should leave open idiosyncratic options, such as Neanderthal and $H$. sapiens co-existence, even adaptive advantages for Neanderthals, as well as late-surviving small-brained species that may or may not have used stone tools.

\section{Stone Tools and Hominin Cognition}

The character of stone tools, if studied with care, can be used to determine aspects of their function and make inferences about their authors. Below we focus on two aspects of cognition connected to lithic technology. First, we look at the cognitive performance of knappers; secondly, we review the available evidence for the trans-generational transmission of knapping strategies. 


\section{Cognitive Requirements of Lithic Technology}

Non-human animals modify stones. Capuchin monkeys have been observed to break stones; grasping them with both hands as 'hammers' to pound on rocks lodged in alluvial deposits. They unintentionally produce flakes while doing this (Profitt et al. 2016). This shows that the cognitive abilities required to modify stones should not be overestimated.

Recent finds in Kenya suggest that basic knapping was perhaps not done by Homo in the region, because thus far the only species found in West Turkana at the same time as the Lomekwian artefacts ( 3.3 Mya) is Kenyanthropus platyops (Harmand et al. 2015; but see Archer et al. 2020 for contextual issues), which some authors group with the australopithecines (e.g. Williams 2017). While the cognitive requirements involved in the production of these stone tools (dubbed Lomekwian) clearly exceed those of the monkeys' pounding behaviour (Lombard et al. 2019), they demonstrate a less thorough understanding of conchoidal fracture and the absence of freehand percussion characteristic of Oldowan (mode 1) assemblages from $\sim 2.6$ Mya.

Although analyses of cognitive performance during stone tool manufacture are debated, a consensus view is emerging that mode 1 assemblages represent some cognitive advances (e.g. Hovers 2012; Toth and Schick 2018; Stout et al. 2019). For example, PET scans of Oldowan toolmaking show that although it is not cognitively challenging, compared with ape tool use, it requires increased visuo-motor demands (Toth and Schick 2018), and it has been suggested that Mode 1 knapping uses an ancestral system dubbed the Anthropoid Object Manipulation Network (Herzlinger et al. 2017). Compared with mode 3 assemblages that require enhanced cognitive capacities (Faisal et al. 2010; Wynn et al. 2017), mode 1 tools are relatively easy to produce.

On the other hand, the cognitive requirements of mode 2 technology are more difficult to characterise because of the great differences in sophistication between early and late LCTs (compare Díez-Martín et al. 2015; Stout et al. 2014). Even though expert modern flint knappers produce a finely retouched handaxe in less than 15 min (Hallos 2005), neurological experiments show that the production of Late Acheulean bifaces requires considerably more cognitive control than mode 1 knapping, as well as a certain level of working memory (Faisal et al. 2010; Putt et al. 2017).

Prepared core, or mode 3 technology is associated with large-brained hominins such as Neanderthals and H. sapiens. Experimental research suggests that the hierarchical organisation of Levallois technology requires different cognitive capacities compared with modes 1 and 2. Mode 3 knapping uses the same neurological mechanisms as language (Eren and Lycett 2012), and may also be cognitively more challenging than mode 4 blade production. For example, Muller et al. (2017) showed that Levallois production consistently required greater hierarchical depth and breadth, as well as more phases through the knapping sequence compared with blade production. In short, mode 3 serves as a prime example of expert cognition, whereas mode 1 and 2 knapping require less expert cognition (Wynn et al. 2017).

Expert cognition draws on long-term memory and some (as opposed to enhanced) working memory. Specifically, it allows the expert to draw on a store of behavioural chains from long-term memory for hierarchical knapping procedures (Wynn et al. 2017). Chimpanzee nut-cracking shows elements of expert cognition, which could 
indicate that it draws on features already present in our last common ancestor - unless it was independently evolved. Mode 1 knapping shows a modest increase for expert cognition, causal cognition, and cognition associated with teaching compared with nutcracking behaviour (Lombard et al. 2019; Wynn et al. 2017). For (esp. later) mode 2 technology, a significant expansion of both long-term and working memory appears necessary (Herzlinger et al. 2017). Further increases in working memory and long-term memory are implicated with the advent of mode 3 technology. Semantic long-term memory also appears necessary (Wynn et al. 2017). These observations indicate how changes in stone tool knapping may have stimulated the development of working memory - or vice versa in a feedback loop-perhaps also effecting changes in brain morphology in both H. sapiens and Neanderthals (Haidle 2010; Wynn and Coolidge 2011; Lombard and Högberg 2021).

\section{Mechanism of Transmission of Lithic Technology}

The inter-generational transmission of knapping strategies is another domain where cognitive skills are key. The mechanisms of transmission are the subject of much debate. For some, the assumption that stone tool knapping is a culturally transmitted phenomenon is weakly supported at best, especially for early industries such as the Oldowan (e.g. Tennie et al. 2017). Even for mode 2 technologies, the standard assumption of a culturally transmitted artefact is contested (Corbey et al. 2016; Tennie et al. 2016). Gärdenfors and Högberg (2017, pp. 188; also see Uomini and Meyer 2013), however, conclude "that stable transmission of the Oldowan technology requires at least teaching by demonstration and that learning the late Acheulean handaxe technology requires at least communicating concepts".

The production of Oldowan, or mode 1 technology, may represent a 'latent solution', continuously being reinvented due to individual learning, supplemented with weak forms of social learning such as stimulus enhancement (Morgan et al. 2015; Shea 2017; Tennie et al. 2017). However, experimental knapping research suggests that demonstration and voluntary practicing of knapping skills are essential to attain mastery also for mode 1 knapping (Gärdenfors and Högberg 2017). Both these elements are unknown in great apes. When compared directly, the teaching modes suggested for bipolar knapping as a form of mode 1 practised at Lomekwi outrank those required for chimpanzee nut-cracking behaviours (Lombard, et al. 2019).

The required transmission mechanisms for mode 2 technology likely vary between early and late variants. Experiments suggest that handaxe shape is too stable to be culturally transmitted because variability is smaller than expected taking copying error into account (Kempe, et al. 2012). Genetic control has been suggested as potential explanation for this phenomenon (e.g. Corbey et al. 2016). However, the same stable transmission has been used to suggest that a cognitive threshold was crossed with the advent of mode 2 technology (Muller et al. 2017). The hierarchical organisation of knapping goals and subgoals is then assumed to point not only to planning ahead but also to the existence of concepts of these goals that would be transmitted semantically (Gärdenfors and Högberg 2017; Herzlinger et al. 2017).

During the Late Acheulean in East Africa, Levallois flake production appears at some sites. At Kapthurin for example, preferential Levallois cleaver flakes are produced using the preferential Levallois technique (Tryon et al. 2005). The knapping of 
mode 3 prepared core technology is cognitively demanding. Moreover, different, discrete variants of prepared core technology are sometimes used concurrently (e.g. Boëda 1988), for example, at Kapthurin, from the early Middle Stone Age, preferential and recurrent Levallois methods co-exist (Tryon et al. 2005). This suggests the active teaching of specific knapping strategies (Gärdenfors and Högberg 2017). Yet, even in the late Middle Palaeolithic, allometric reduction sequences result in the production of a range of typological tool types, which are all expressions of a single functional concept (Weiss et al. 2018). This is reinforced by experiments demonstrating core-forms resembling prepared cores can be produced using very simple knapping methods (Moore and Perston 2016). The ratio between prepared cores and preferential removals in assemblages is sometimes low (Akhilesh et al. 2018, supplementary table 1), suggesting that typological mode 3 cores did not always function in a mode 3 chaîne opératoire.

The foregoing suggests that cultural control of toolmaking cannot always be assumed and that hierarchically organised engineering could be under genetic control (Allen et al. 2003). Hence, hierarchically organised reduction sequences per se may not be sufficient evidence to support cultural transmission mechanisms, unless we assume that prehistoric hominins were so similar to modern test subjects that modern knapping experiments give a reliable impression of required transmission mechanisms. Even if artefacts are products of cultural transmission, some types may not represent a mental template, but may be an emergent property of basic knapping practices (McPherron 2000). We can therefore not assume that one single transmission mechanism was used and elaborated across hominin species. Different species likely employed different transmission strategies for similar-looking stone tool assemblages. Mode 1 assemblages may have been a latent solution in Australopithecines or H. habilis, while the evolution of more elaborate transmission systems may have been associated with the need for increased fidelity of transmission in other species such as H. ergaster.

\section{The South African Archaeological Record}

The Middle Pleistocene has been dubbed 'the muddle in the middle' due to the lack of cultural and technological trends (Isaac 1975). In southern Africa, much of the Middle Pleistocene record is represented in surface contexts, complicating interpretation. Nonetheless, South African Acheulean assemblages have been studied for over a century (Goodwin and Van Riet Lowe 1929; Peringuey 1911). Chronological advances are being made, especially with assemblages coming from fluviatile contexts (e.g. Lotter and Kuman 2017; Lotter 2020a,b), and technological studies reveal important insights into the development of prepared core technology in South Africa (e.g. Li et al. 2017; Porat et al. 2010; Wilkins et al. 2010), which was introduced across the region during the timeframe proposed for $H$. naledi. However, the beginning of the Middle Stone Age was not a simple technological replacement of one industry by another. Other modes of toolmaking continued to be practised. A synthesis of the South African Stone Age techno-cultural sequence based on dated sites only (Lombard, et al. 2012), reveals that multiple industries are present in South Africa (Table 3).

The early Middle Stone Age (dated to 300-130 ka) represents an informally designated group of assemblages with limited information on their characteristics (Lombard et al. 2012). A common factor of the assemblages is the presence of some 
form of prepared core technology and blade production (i.e. discoidal and/or Levallois). Four sites across South Africa have dates overlapping with H. naledi, including Florisbad (Kuman et al. 1999; Meiring 1956). Another notable occurrence is Sterkfontein in the Cradle of Humankind, not far from where H. naledi was found, with an age estimate of 294-210 ka (Ogola 2009; Reynolds et al. 2007).

Second, the Earlier-Middle Stone Age transition (dated to $\sim 600-200 \mathrm{ka}$ ) contains so-called Sangoan and Fauresmith industries that may be transitional between the Earlier and Middle Stone Ages. A re-appraisal suggests that such assemblages contain many Middle Stone Age technological characteristics (Herries 2011). The assemblages have evidence for the use of prepared core technology, combined with the production of large bifacial cutting tools. Only five dated sites in South Africa have been assigned to this phase (Lombard, et al. 2012). However, many undated sites/contexts with both early Middle Stone Age and Earlier-Middle Stone Age transitional assemblages are present on the broader landscape. Some of the assemblages show signs of mixing and dating is problematic; in some cases, the material may be younger than the dates proposed for $H$. naledi (Herries 2011 also see discussion on the Fauresmith at Wonderwerk in Chazan 2015).

Finally, some Earlier Stone Age Acheulean assemblages (dated to 1.5 Mya to approximately $300 \mathrm{ka}$ ) overlap with the dating of the $H$. naledi remains, notably those at Duinefontein (Cruz-Uribe et al. 2003; Feathers 2002) and Rooidam (Szabo and Butzer 1979). Within the Acheulean, the poorly dated and described Victoria West technology has been proposed to represent the earliest prepared core technology ( $\mathrm{Li}$ et al. 2017), which could suggest deep roots for such technologies in southern Africa. For example, Beaumont and Vogel (2006) proposed that proper Victoria West cores are always preferential cores and that they could date to 1 Ma (also see Lotter 2020b). However, these cores are also argued to be similar to Acheulean bifaces, and as such an extension of mode 2 knapping strategies (Lycett et al. 2010).

This brief overview shows that the late Middle Pleistocene record contains much variability. Mode 3 and mode 2 assemblages were both produced between $330 \mathrm{ka}$ and $230 \mathrm{ka}$ in southern Africa, while stratified contexts further afield (McBrearty 2005; Shea 2011) suggest that expedient mode 1 knapping continued to be produced/used. Moreover, we should not reify the Acheulean and Middle Stone Age. The presence of prepared-core-like technologies such as Victoria West in the Acheulean shows that these entities were not homogeneous across the subcontinent (Mercader et al. 2016; Lotter 2020b; Lotter et al. 2016).

\section{Case Study: Homo naledi and Homo sapiens in Southern Africa}

The discovery and dating of $H$. naledi complicate the interpretation of the southern African archaeological record because it implicates that a small-brained species (Berger et al. 2015; Dirks et al. 2015), was sympatric with large-brained H. sapiens sensu lato in southern Africa (Lombard et al. 2018). The species was discovered in a deep cave context near Johannesburg, South Africa. Based on its primitive anatomical characters it was originally anticipated that $H$. naledi would shed light on the "early evolution of humans and their close relatives" (Berger et al. 2015, pp. 3). A dating programme subsequently constrained the likely age of the fossil deposit to between 335 and 236 $\mathrm{ka}$ - the late Middle Pleistocene (Dirks et al. 2017). 
Berger et al. (2017) argue that $H$. naledi is a potential author of prepared core technology typical of the Middle Stone Age. For example, they say: "H. naledi has traits that were long considered to be adaptations for creating material culture. Its wrist, hand and fingertip morphology share several derived features with Neanderthals and modern humans that are absent in $H$. habilis, H. floresiensis, and Au. sediba (Kivell et al., 2015). If these features evolved to support habitual tool manufacture in Neanderthals and modern humans, then it is reasonable to conclude that $H$. naledi was also fully competent in using tools" (Berger et al. 2017: 9). "MSA variants are characterized by the manufacture of blades and by the presence of the Levallois flaking technique and hafted implements [...]" (Berger et al. 2017:10). "Considering the context, it is possible that H. naledi sustained MSA traditions" (Berger et al. 2017: 10). Yet, as already mentioned, large-brained taxa (Neanderthals, H. sapiens, H. heidelbergensis) are widely accepted as makers of such Levallois (mode 3) technologies (e.g. Eren and Lycett 2012).

Here we review the available anatomical, ecological and archaeological information and consider the ecological niches of both $H$. naledi and $H$. sapiens to constrain the likely techno-behaviours of $H$. naledi. We do not suggest that both species evolved sympatrically. H. naledi may have evolved in geographic isolation from the encephalising African populations. However, based on the radiometric age estimates, by the Middle Pleistocene, they were sufficiently differentiated to co-exist in the same biome.

\section{Homo naledi Taphonomy and Dating}

The co-existence of $H$. sapiens (archaic and/or modern) and very small-brained $H$. naledi in South Africa's grassland biome, depends on the taphonomic context and accuracy of the dating of the Rising Star skeletal material. The context of the initially reported remains of $H$. naledi is unique. They were found in a hard-toreach location deep within the Rising Star cave (the Dinaledi Chamber), in nonbrecciated deposits devoid of other macro-vertebrate remains and with no cultural remains (Dirks et al. 2015; Dirks et al. 2017). The discoverers suggest this is the result of intentional disposal of the bodies (Dirks et al. 2015). However, a comparison of the Dinaledi skeletal element representation with that of bone assemblages of known origin suggests it could also be a natural death assemblage or a scavenged assemblage (Egeland et al. 2018; Nel et al. in press). As most bones' surfaces are badly preserved, and only a subset of the material has been microscopically examined for carnivore damage a definitive assessment cannot be made (Egeland et al. 2018, also see Val 2016). Natural mechanisms of deposition, for example water-borne deposition of the remains, have also been mooted (Val 2016: 146). Nonetheless, conditions in the Dinaledi chamber appear to have been dry for a considerable period (estimated at least $300 \mathrm{ka}$ ) as gauged from the rate of in situ ongoing brecciation of the sediments (Wiersma et al. 2020).

Subsequent discoveries of $H$. naledi remains in a different location of the same cave system (the Lesedi chamber) are in open association with faunal remains - but no cultural objects (Hawks et al. 2017). The faunal assemblage, which may not be contemporary with the $H$. naledi remains, is dominated by medium-sized carnivores (Canis, Vulpes, Felis); micro-mammals were also recovered (Hawks, et al. 2017). The remains were only announced at genus-level and do not yet provide specific environmental or age-related information. 
Several methods were employed to arrive at an age estimate of the $H$. naledi remains from the Dinaledi Chamber. Direct assays on H. naledi remains were conducted using radiocarbon, U-Th and U-series ESR dating; flowstones related to the depositional context of $H$. naledi were dated using U-Th estimates and palaeomagnetism, while OSL dating was used on a quartz-bearing layer. Collectively, these approaches yielded an estimated age of between 335 and $236 \mathrm{ka}$ for the deposition of the remains in the Dinaledi Chamber (Dirks et al. 2017).

Radiocarbon dating yielded ages of $\sim 33 \mathrm{ka}$ and $\sim 35 \mathrm{ka}$ instead of the expected infinite ages, possibly as a result of late precipitation of calcite in the fossils. Based on the results of other techniques, these dates appear too young. U-series ESR dates obtained independently in two different laboratories yield an estimated age range of 335-139 ka for the deposition of $H$. naledi remains. U-Th dating places $H$. naledi teeth between 200 and $70 \mathrm{ka}$ (Dirks et al. 2017). OSL dates were taken from multiple-grain aliquots and represent averages of the grains in these aliquots. The difference between aliquots suggests that not all grains were fully bleached. As incompletely bleached grains would yield too early ages the team prefers a minimum age model. The OSL dates suggest the Dinaledi skeletal material was deposited between $353 \mathrm{ka}$ and $241 \mathrm{ka}$ (Dirks et al. 2017).

Flowstones overlying and encasing $H$. naledi bone yield ages from $242 \mathrm{ka}$, suggesting that their deposition occurred prior to that time. A potential problem is that erosion and re-deposition is evidenced in the deposits (Dirks et al. 2015, and see comments by Val 2016). However, conditions in the chamber are estimated to have been dry for at least the last $300 \mathrm{ka}$ (Wiersma et al. 2020). Further, the flowstoneencased bone suggests the terminus ante quem is valid. Moreover, some remains are in anatomical context and the sample of studied bone surfaces is not severely weathered (although this sample only forms a small part of the assemblage, see Val 2016: 147; also see Nel et al. in press). This suggests that, although the remains may not be in primary depositional context, they were deposited in the Dinaledi chamber relatively quickly after death and hence this does not invalidate the terminus post-quem. Makhubela et al. (2019), however, draw attention to possible complications regarding the effects of long soil surface residence times on cosmogenic nuclide denudation rates in the Cradle of Humankind. Based on the published age assessments, which have not yet been empirically challenged, we see a late Middle Pleistocene age for the Dinaledi chamber remains as a plausible scenario, and stimulus for consequential speculation/theorising.

\section{Anatomical Features of Homo naledi and Their Implications}

$H$. naledi is one of the best described hominins to-date, with information from multiple specimens for all physiological traits (Hawks et al. 2017). It presents a mosaic of primitive and derived anatomical characteristics. We review the ecological and technological implications of its anatomy, summarised in Table 2.

Body Size $H$. naledi's reconstructed body mass overlaps with the lower range of $H$. erectus, but its mean weight $(37.5 \mathrm{~kg})$ is much lower than that of other Late and Middle Pleistocene Homo species (Pleistocene H. sapiens mean $67.2 \mathrm{~kg}$ ). Its stature was also much smaller $(142.2 \mathrm{~cm})$ than that of other Late and Middle Pleistocene Homo 


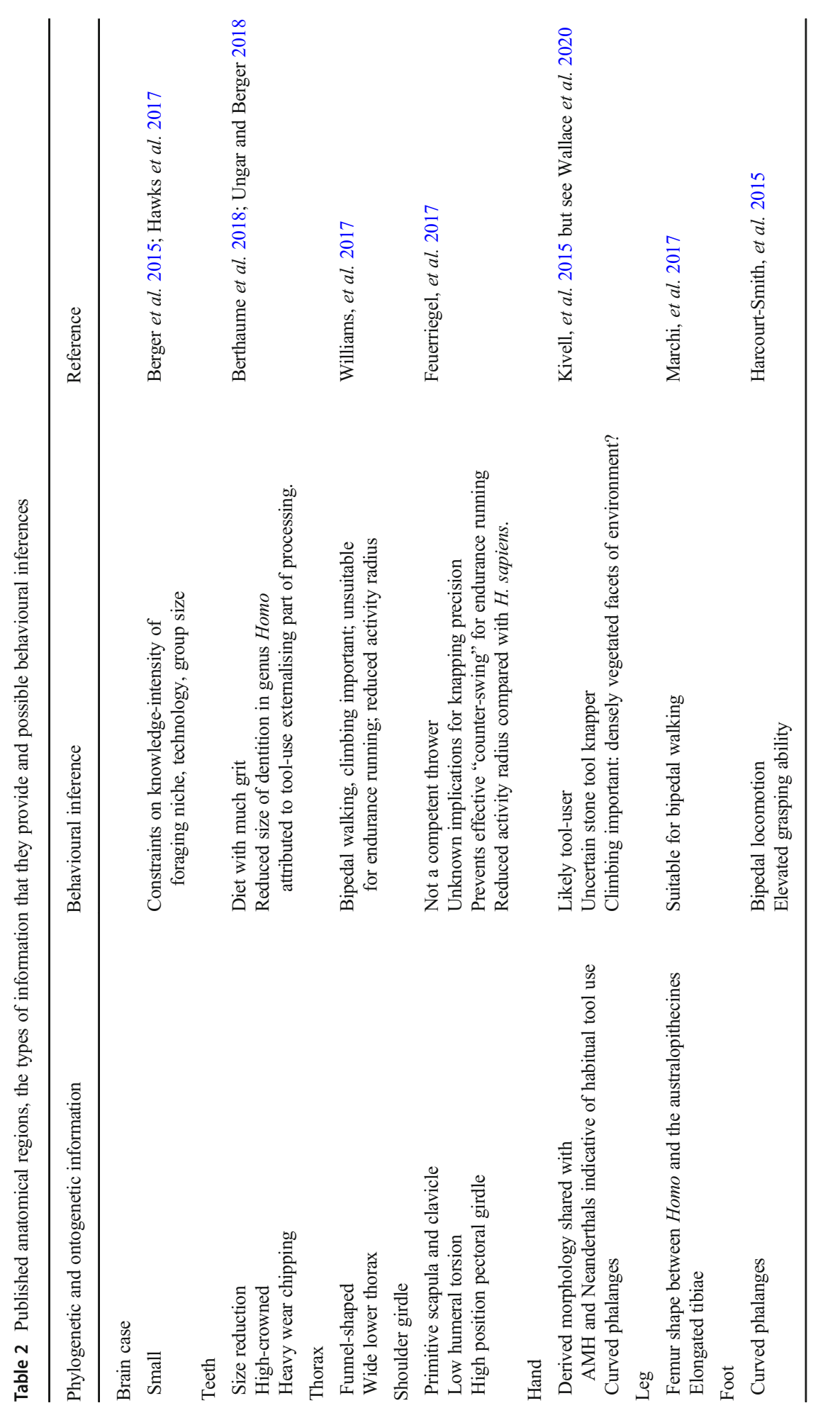


species (H. sapiens mean $170.3 \mathrm{~cm}$ ) and overlaps with the lower range of $H$. erectus (Berger et al. 2015; Hawks et al. 2017; Will et al. 2017). The small body size has implications for land-use and foraging strategies.

Brain Size The estimated endocranial volume of $H$. naledi specimens is $465-610 \mathrm{~cm}^{3}$ (Fig. 2) (Berger, et al. 2015; Hawks et al. 2017). H. naledi thus had smaller brains than Homo habilis (Spoor et al. 2015). However, its brain anatomy shares derived morphology with $H$. habilis, $H$. erectus and $H$. floresiensis. This is interpreted as a result of reliance on tool use in the genus Homo (Holloway et al. 2018). Prior to H. naledi's discovery, only large-brained hominin fossils (Table 1) were known from the African Middle Pleistocene. The persistence of a small-brained species until the late Middle Pleistocene challenges ideas on the importance of encephalisation for hominin niches. Encephalising hominins faced strong selective pressure favouring increased brain size, as large brains come at a cost. They are so-called expensive tissues, accounting for a large proportion of human energy expenditure (Aiello and Wheeler 1995). Energetic demands are highest for pregnant and lactating females (Aiello and Key 2002; Kaplan et al. 2000; Leonard et al. 2003). To 'finance' larger brains, improved dietary quality, likely resulting in increased meat consumption, and provisioning of pregnant and lactating females were needed (Leonard et al. 2003). As a result, hunter-gatherers rely much more than apes on extracted foods (e.g. underground storage organs, honey, etc.) and meat (Kaplan et al. 2000). Increased dietary quality in turn may have resulted in an increased basal metabolic rate and increased fat storage to accommodate bigger brains (Kaplan et al. 2000; Leonard et al. 2003; Navarrete et al. 2011; Pontzer et al. 2016).

Two main driving forces have been proposed for hominin encephalisation, namely an expanding social network (Dunbar 1992), and an increasingly multi-dimensional foraging niche (DeCasien et al. 2017). Reliance on complex technology forms an

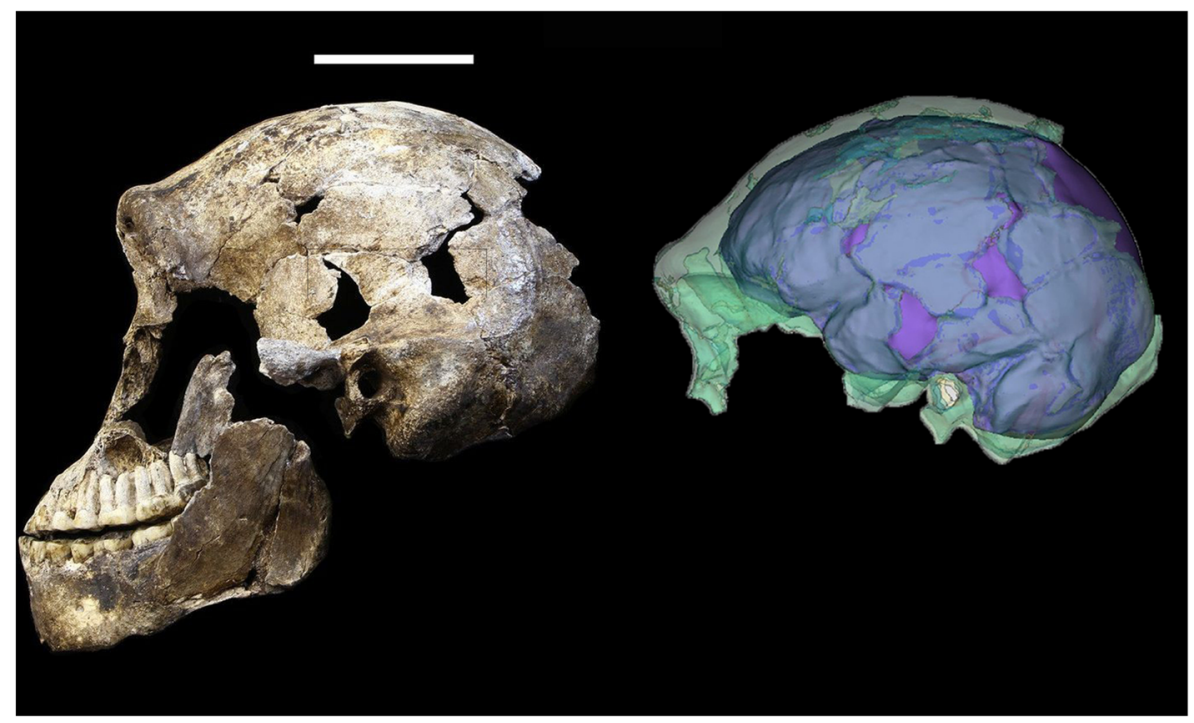

Fig. 2 Homo naledi skull illustrated by Lesedi 1 fossil and virtual reconstruction of endocranial volume of 610 ml. Modified from Hawks et al. (2017, Fig. 5, Fig. 6), published under CC-BY licence https:// creativecommons.org/licenses/by/4.0/ 
extension of the foraging niche hypothesis. Toolmaking ability was likely targeted by selection as tool-use became crucial in determining foraging success (cf. Shea 2017; Stout and Khreisheh 2015). H. naledi's small brain suggests that its niche was much less social and/or knowledge-intensive than that of early $H$. sapiens. Its shared morphology with $H$. habilis, $H$. erectus and $H$. floresiensis may be the result of tool use (but also see Bruner 2021 and Lombard and Högberg 2021 for aspects of the sapient brain and technology). However, it could also be an inherited feature from an early Homo ancestor, no longer actively under selection.

Dentition Dentition preserves both phylogenetic and ontogenetic information. Dental anatomy informs on inherited dietary adaptations (Irish et al. 2018), but tooth wear also reveals evidence for the realised diets of the sampled individuals (Berthaume et al. 2018; Towle et al. 2017). The genus Homo exhibits reduced postcanine dentition compared with australopithecines, possibly due to increased external food processing with tools. $H$. naledi conforms to this trend, exhibiting reduced molar size (Berger et al. 2015; Berthaume et al. 2018). Further, their teeth are high-crowned and wear-resistant; the likely result of selection for increased longevity of the teeth (Berthaume et al. 2018). Also, some anatomic features suggest that compared with apes and Plio-Pleistocene Homo sp. fossils, H. naledi (together with Paranthropus and Australopithecus) teeth produced larger shear forces. This points to processing of foods higher in structural fibres (Berthaume et al. 2018). Analysis of H. naledi tooth wear reveals a high degree of chipping on both premolars and molars. This is likely related to dietary quality, not to object manipulation. The chipping indicates lower dietary quality than in Australopithecus africanus and Paranthropus robustus (Towle et al. 2017). The probable cause is a diet containing tough materials such as nuts or shells, or a high incidence of contaminants, such as grit (Towle et al. 2017). Further analysis of the wear patterns confirms this (Ungar and Berger 2018). On the whole, $H$. naledi's dental evidence suggests the consumption of hard plant foods, grit adhering to foodstuffs, and likely a lower degree of processing of foods compared with other Homo species.

Limb Anatomy and Locomotion $H$. naledi's limb anatomy shows a mosaic of adaptations to bipedal walking and climbing. The shoulder girdle was in an ape-like position and the humerus had low torsion-both adaptations towards habitual climbing, preventing counter-rotation of the arms needed to stabilise the trunk during endurance running (Feuerriegel et al. 2017). The anatomy of the upper limb also excludes competent overarm throwing in H. naledi (Feuerriegel et al. 2017). The vertebra and ribs reveal a funnel-shaped thorax that also complicates endurance running and can be interpreted as a climbing adaptation (Williams et al. 2017). Climbing was therefore important throughout $H$. naledi's evolutionary history and may have counteracted selection pressures favouring a barrel-shaped thorax for more effective bipedal locomotion.

Similar to that of apes, $H$. naledi's phalanges are long and curved, which is a response to climbing and suspension. The degree of curvature is generally thought to develop ontogenetically, suggesting that $H$. naledi's phalanges demonstrate that the excavated individuals actively engaged in climbing (Kivell et al. 2015). However, the phalanges of a chimpanzee raised in a human home and trained to walk on two legs 
with limited climbing opportunities, show a similar degree of curvature to those of wild chimpanzees (Wallace et al. 2020). It is therefore possible that the curved phalanges in $H$. naledi represents an inherited feature instead of definitive evidence that the individuals recovered in the Dinaledi chamber were intensive climbers. The retention of this feature by $H$. naledi (in contrast to other Homo species), however, suggests that climbing played an important role in their evolutionary history while the lower limb anatomy demonstrates derived morphology enabling efficient bipedal locomotion. The femur shape clusters between Homo and the australopithecines, with elongated tibiae, indicative of long lower limbs (Marchi, et al. 2017; also see Steudel-Numbers and Tilkens 2004). The foot of $H$. naledi exhibits a morphology that is similar in many respects to the $H$. sapiens foot and is suitable for striding bipedalism. However, the proximal phalanges of the foot are notably more curved than in H. sapiens (HarcourtSmith et al. 2015).

In short, $H$. naledi's limb anatomy indicates that they relied on both bipedal locomotion and habitual climbing. Lack of evidence for endurance running, which is critical for both active scavenging and endurance hunting in open environments (Blumenschine 1987; Liebenberg 2006; Lieberman et al. 2007), points to a more limited foraging radius for $H$. naledi compared with $H$. sapiens and its large-brained forebears. The upper limb demonstrates that $H$. naledi was better adapted to climbing than other members of Homo, which could imply a dependence on resources, or resting locations that were 'hard-to-reach' for other hominins or predators.

Limb, Hand Anatomy and Tool Use The derived morphology of the H. naled $i$ wrist and hand show a mixture of derived and primitive features, and is one of the main arguments put forward in favour of its 'habitual' tool use (Feuerriegel et al. 2017, pp. 171). Characteristics such as a long thumb and a wrist configuration shared with Neanderthals and $H$. sapiens imply to some that $H$. naledi was a committed, habitual tool-user capable of forceful precision grips (Kivell et al. 2015). Yet, other features associated with behaviours such as tool use and throwing are lacking, for example, the absence of a styloid process in the 3rd metacarpal (Key 2016; Kivell et al. 2015) to stabilise the 'central part of the palm against external volar forces' during knapping with hand-held hammerstones (Marzke 2013, pp. 4). Further upper limb anatomy also has implications for tool use and manufacture, and experimental work suggests that knapping precision shows parallels to throwing when it comes to upper limb kinematics and the role of the wrist (Williams et al. 2010). H. naledi likely had limited throwing capabilities (Feuerriegel et al. 2017, pp. 172), and although the exact advantages of derived $H$. sapiens upper limb morphology in knapping remain under-researched (Williams et al. 2014, pp. 53), it is possible that the shoulder configuration of $H$. naledi and the limited amount of humeral torsion could have impacted knapping precision.

The combination of derived features facilitating tool use and indications for intensive arboreal locomotion is unknown in other hominins. As such, it is unclear if there is a loss of functionality implied for either behaviour in H. naledi (Kivell et al. 2015). Some of the derived anatomy was likely inherited from the common ancestor of $H$. naledi and its closest relatives H. antecessor and H. erectus (Dembo, et al. 2016). But due to the rarity of fossil hands (Kivell, et al. 2015), it is unclear to what degree 
$H$. naledi's wrist anatomy was inherited and to what degree $H$. naledi was itself under selection for an effective precision grip.

\section{Homo naledi and Homo sapiens as Sympatric During the Late Middle Pleistocene}

The relevant fossils and dated artefact assemblages are sparsely distributed (see Table 3). Aside from the H. naledi remains, the Florisbad skull is most informative. Florisbad is located about $300 \mathrm{~km}$ southwest of the Cradle of Humankind where H. naledi was found; both sites are in the current Grassland Biome (Fig. 3) (Mucina and Rutherford 2006). Moreover, the Middle Stone Age stone tools from the Florisbad site occur widely on the Grassland Biome including the Cradle of Humankind (esp. taking into account the open air record [Caruana 2017; Moll 2017]) (for overviews see Lombard, et al. 2012; Mason 1962; Volman 1981; Wadley 2015; also see Sampson 1974). It is, however, relevant to note that the location in Florisbad where the hominin was recovered is a redistributed spring deposit, so that its direct association with the archaeological material remains to be verified. The only other African hominins with a radiometrically determined age contemporaneous to that of $H$. naledi are the archaic H. sapiens individuals from Jebel Irhoud, Morocco, dated to $286 \pm 32 \mathrm{ka}$ (Hublin et al. 2017), and the Broken Hill skull in Zambia dated to $299 \pm 25 \mathrm{ka}$ (Grün et al. 2020).

The presence of multiple hominin lineages on the African continent during the late Middle Pleistocene has also been established by the introgression of archaic DNA into H. sapiens genomes (Hammer et al. 2011). Previously, it was assumed that these populations were not sympatric (Scerri et al. 2018). Further, it was assumed that the populations living in different parts of Africa derived from a relatively large-brained common ancestor (Hammer et al. 2011). Reconstruction of the full genome of Holocene Later Stone Age individuals from KwaZulu-Natal in South Africa indicates that H. sapiens was present in sub-Saharan Africa from perhaps as early as $350 \mathrm{ka}$ (Schlebusch et al. 2017; Schlebusch et al. 2020).

However sparse the fossil record, if the Rising Star age estimate is correct, it suggests that $H$. naledi and $H$. sapiens sensu lato were sympatric in the Grassland Biome during the Late Middle Pleistocene. Competitive exclusion would lead to the local extinction of overlapping hominins, unless their niches were sufficiently differentiated (Banks et al. 2008). Hence, some form of niche separation must have existed. We do not know the duration of coexistence, as the rich $H$. naledi assemblage from the Dinaledi chamber is thus far the only record of this species with an age estimate. We also do not know where either species evolved, nor do we assume that the Grassland Biome was their core habitat. The two species may have developed separately only to become sympatric after a period of geographic separation. This increases the likelihood of divergent niche development allowing subsequent co-existence in South Africa during the Late Middle Pleistocene.

\section{Middle Pleistocene Ecological Context}

The late Middle Pleistocene date places $H$. naledi in the Florisian land mammal age, although such placement would be more secure once associated fauna is found. During 


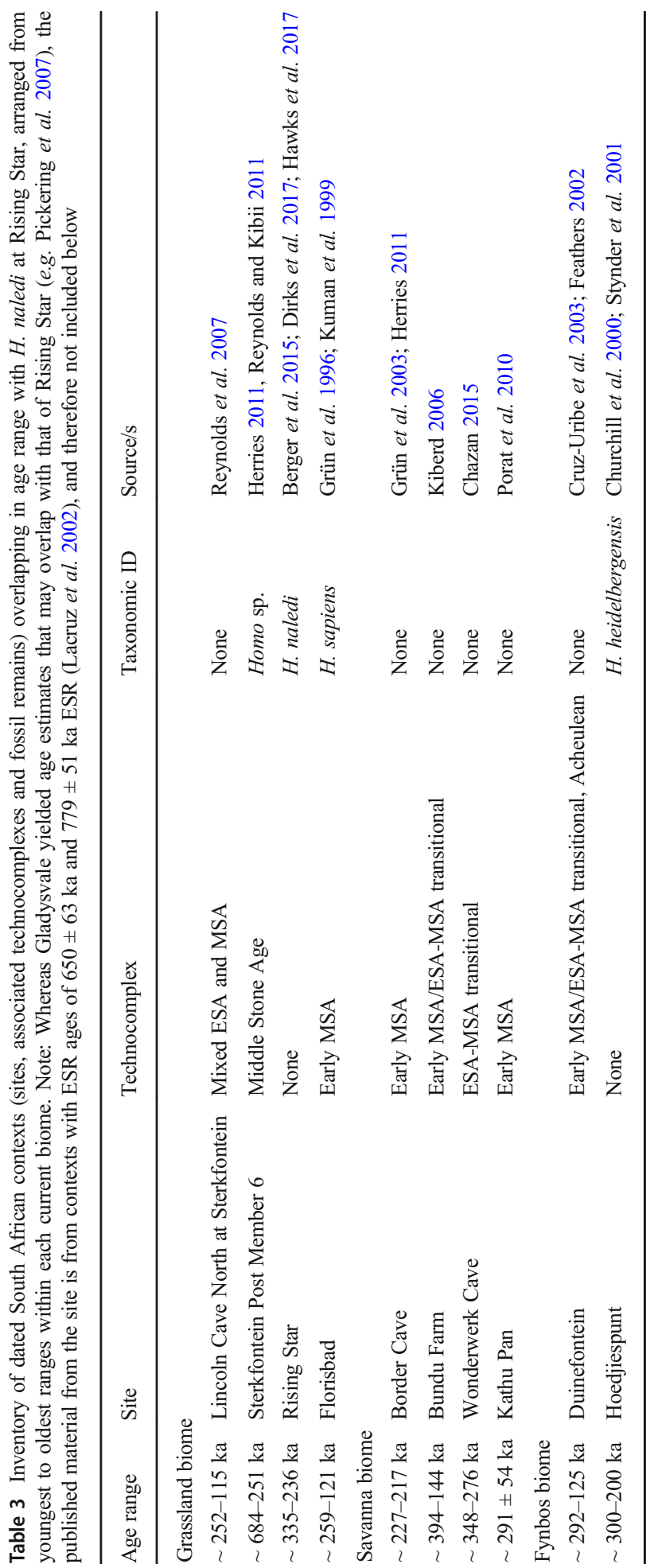




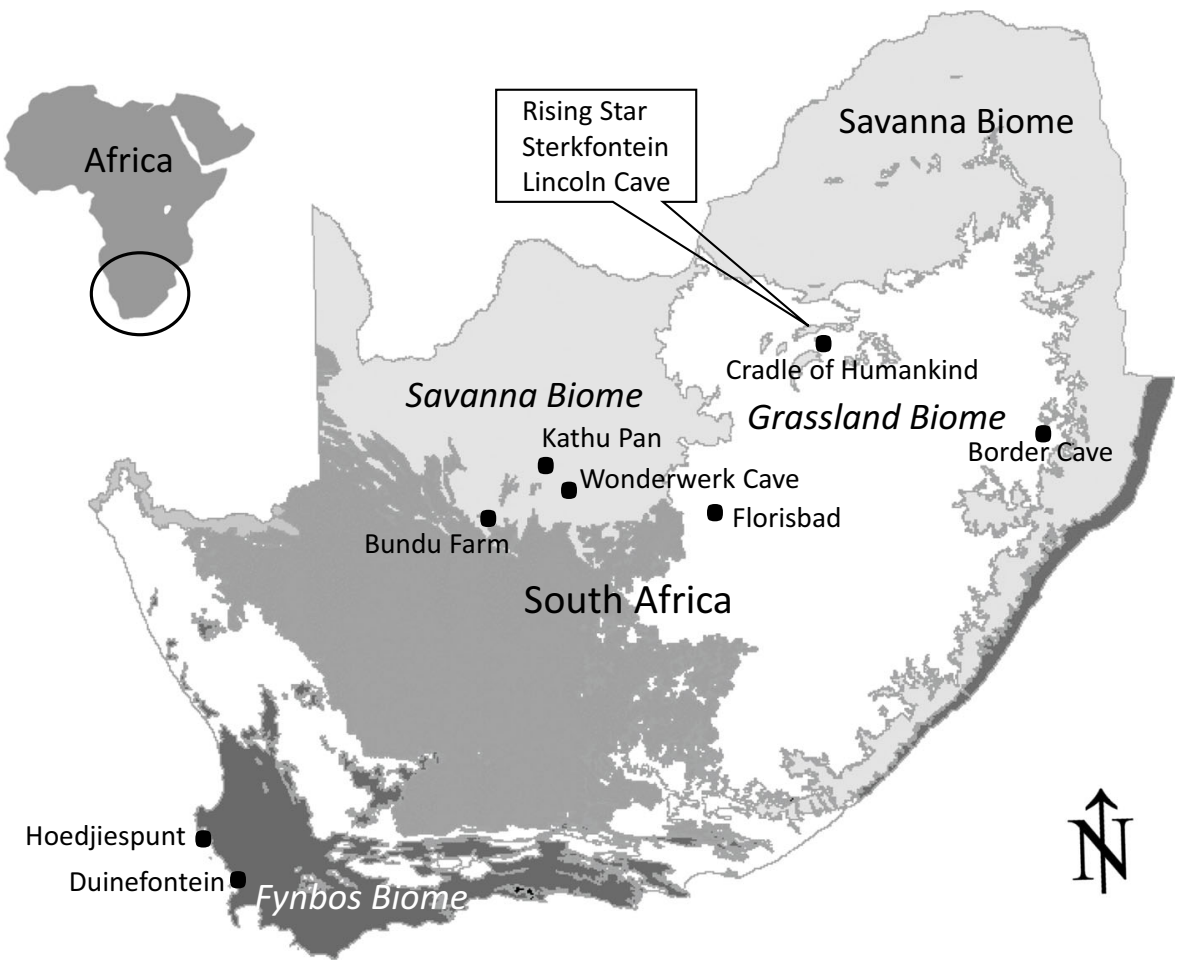

Fig. 3 Map of the South African biomes following Mucina and Rutherford (2006) with important fossil and archaeological sites mentioned in the text.

the Florisian, South Africa's central interior environment was characterised by extensive grasslands. Compared with the late Lower Pleistocene, the Middle Pleistocene saw a progressive opening up of the vegetation and increased importance of $\mathrm{C} 4$ plants in ungulate diets, reflecting a dominance of grasslands (Codron et al. 2008). Today, the central grasslands are comparatively dry, but by correlating the pollen stratigraphy at the Florisbad site, Scott et al. (2019) found that the lower layers containing the Florisbad fossil and its associated Middle Pleistocene fauna, experienced cool moist and grassy conditions. The contemporaneous occurrence of nine extant (Equus quagga, Ceratotherium simum, Phacochoerus aethiopicus, Ph. africanus, Hippopotamus amphibius, Syncerus antiquus, Damaliscus pygargus, Alcelaphus buselaphus, and Connochaetes gnou) and six extinct species of grazers (Equus capensis, E. lylei, Megalotragus priscus, Pelorovis antiquus, Damaliscus niro, and Antidorcas bondi) reflect a highly productive open grassland ecosystem (Manegold and Brink 2011). It has been suggested that these species interacted in a system of grazing succession similar to what has been described for the Serengeti (Brink 2005; Codron et al. 2008).

Together with geological evidence, the wetland component of the Florisian faunas can be interpreted to reflect the presence of perennial lakes (Brink 2005), with the seasonal pans of the modern grassland a relict of the Florisian palaeolake system (Manegold and Brink 2011). The Middle and early Late Pleistocene grasslands of central southern Africa were therefore considerably more productive than today, so that a number of water-loving taxa were present where they are currently unknown (Brink 
2016). Two Middle Pleistocene faunal assemblages are known from the immediate vicinity of Rising Star Cave, namely the Gladysvale external deposits and Lincoln Cave at Sterkfontein (Lacruz et al. 2002; Reynolds et al. 2007). Both support the presence of extensive grasslands. The Lincoln Cave Sterkfontein fauna suggests that part of the assemblage was accumulated in a wet period (Reynolds et al. 2007).

\section{Constraining H. naledi Techno-behaviours}

Based on the foregoing review we move on to an evaluation of $H$. naledi's likely technological niche. We follow Shea's (2017) suggestion of connecting evolutionary selective pressures to stone tool knapping abilities represented in archaeological assemblages. We assess three distinct hypotheses. First, H. naledi did not knap stone tools, but used organic technology or unmodified stones to aid in the exploitation of extracted resources. Secondly, H. naledi practised tool use as a routine (habitually), but stereotyped part of their adaptation (sensu Shea 2017). This could have been associated with mode 1 or 2 technology. Thirdly, knapped tool use was obligatory for $H$. naledi, with severe negative fitness consequences for individuals that were not taught to produce stone tools (Shea 2017). This crucial role for the technological niche is associated with mode 3 technology, a hypothesis considered a distinct possibility by Berger et al. (2017).

Hypothesis 1. Homo naledi did not produce knapped stone tools, but used unmodified tools

From an archaeological point of view this ought to be the null hypothesis since H. naledi remains are thus far not associated with any stone artefacts (Dirks et al. 2017; Hawks et al. 2017) although its hand shares many derived characteristics with the hands of habitual tool users (Hawks et al. 2017; Kivell et al. 2015). Many of these features have long been "considered adaptations for creating material culture" (Berger et al. 2017, pp. 9). This derived anatomy suggests that at some point during H. naledi's evolutionary history, its hands were under selective pressure for effective tool use. However, selective pressures for efficient tool use do not automatically imply the production of knapped stone tools. It could simply indicate the use of organic tools and/or unmodified stones as seen in living primates. Percussive technology (in the form of unmodified hammerstones) is pervasive in the archaeological record, comprising "one of the longest-standing traditions of tool use in human evolution" (Caruana et al. 2014, pp. 2). Such tool use could yield important fitness benefits and hence selection pressures favouring changes in hand anatomy.

To us, it is important to distinguish between 'using' tools and 'knapping' stone tools, because habitually using tools may affect hominin body and brain morphology (cf. Holloway et al. 2018), as well as cognition, but it does not automatically imply the production or knapping of stone artefacts. Taking the phylogeny of H. naledi into account as well as the derived features of its hand-shared with H. neanderthalensis and $H$. sapiens - it is likely that they were occasional or habitual tool 'users' (Kivell et al. 2015), perhaps also of unmodified organic wood or bone artefacts. We contend that there is a long way to go before a conflation between 'tool use and manipulation' 
and 'deliberate technical production' can be considered robust. Archaeologically, this hypothesis is difficult to evaluate. More research on non-knapped and organic object use is needed.

\section{Hypothesis 2. Homo naledi used simple knapped stone tools}

The derived features of $H$. naledi's hand could indicate that they were occasional or habitual tool users, corresponding to the production of mode 1 or mode 2 lithic technologies (sensu Shea 2017). Shea (2017) suggests that occasional and habitual tool use brings fitness benefits. He associates occasional tool-use with the use of bipolar technology, pebble core reduction, and simple platform core reduction, resulting in stone artefacts strongly constrained by raw material availability. Habitual tool use is associated with more elaborate reduction sequences that modern novices generally cannot 'reverse engineer', needing instruction for successful production (Shea 2017; see also Gärdenfors and Högberg 2017; Morgan, et al. 2015). Even today many people are adept tool users - but not so much when it comes to technical conceptualisation and/or production. Hence these abilities may represent distinct aspects of any hominin's niche.

We argue that the derived wrist anatomy in itself is not sufficient evidence to demonstrate the production of knapped stone tools in $H$. naledi as it may not have been under active selection but rather an inherited feature. Also, the use of non-knapped tools may produce similar selective pressures. This hypothesis is archaeologically challenging because current classification underestimates the variability of lithic reduction sequences that were used. And because bipolar technology, pebble core reduction, and simple platform core reduction strategies associated with habitual tool use, are all found within the area where H. naledi lived (e.g. Caruana 2017). Their dating and association with hominin groups is ambiguous at best.

\section{Hypothesis 3. Homo naledi was an obligatory tool user}

Temporally, H. naledi overlaps with Middle Stone Age assemblages and its potential authorship should be considered. However, there are multiple technocomplexes and hominin populations on the South African landscape (Table 3; Dusseldorp et al. 2013). Until $H$. naledi is stratigraphically associated with diagnostic Levallois-type stone artefacts, we cannot be certain about their producing and using them, and have to consider the use of other tools as best-fit scenarios.

Prepared core knapping requires more than derived hand and wrist anatomy. The knowledge intensity of Levallois reduction sequences is much greater than that of modes 1,2 , and 4 (see discussion above). With an average brain size smaller than H. habilis (a Mode 1 producer) we deem this hypothesis unlikely. Our reading is reinforced by the fact that mode 3-type artefacts were often hafted to be utilised effectively as hunting spears or butchery knives (e.g. Lombard 2005; Lenoir and Villa 2006; Wilkins et al. 2012; Sahle et al. 2013), representing an intricate and knowledge-intensive procedure (Barham 2013; Haidle et al. 2015; Kozowyk et al. 2016; Lombard and Haidle 2012; Wadley et al. 2009). The temporal overlap with the occurrence of mode 3 artefacts is insufficient evidence to confirm the hypothesis that $H$. naledi produced such artefacts. We contend that there is not enough archaeological 
nor other supporting evidence to classify $H$. naledi as an obligatory tool user and a knapper of mode 3 technology. To us, the previously discussed hypotheses of nonknapped tool use or very basic knapping better fit explanations that adhere to the principle of parsimony, and therefore require the fewest possible unverified assumptions.

\section{On Homo sapiens and Homo naledi Ecological Niches in South Africa}

Any consideration of the production and or use of stone tools by late Middle Pleistocene H. sapiens (archaic or modern) and H. naledi should take into account their ecofunctional role. Knapped stone tool production is not automatic in Homo. It may be 'lost' in hominin lineages and tools from other materials may be fashioned, as happened in some $H$. erectus populations (Joordens et al. 2015). Below, we expand our suggestions on $H$. naledi tool use by fleshing out their ecological niches.

\section{Homo sapiens}

The Florisbad fossil is currently the only hominin specimen of similar age to H. naledi (Table 3), but South Africa boasts the richest H. sapiens record dated between $\sim 120 \mathrm{ka}$ and $50 \mathrm{ka}$ on the African continent (Grine 2000; Grine and Henshilwood 2002; Marean et al. 2004; Millard 2006; Verna et al. 2013; Grine et al. 2017; Riga et al. 2018; Will et al. 2019). All archaeological sites with human remains dating to this time have bona fide mode 3 and/or mode 4 technologies. Thus, there can be no question about the association between $H$. sapiens and the production of mode 3 technology. H. sapiens was an obligate tool-user, reliant on activities that could not be accomplished otherwise; their tools brought them considerable fitness benefits.

One activity requiring sophisticated tool use is hunting. Based on the archaeological record, ecological modelling and experimental work, active hunting was an important strategy for $H$. sapiens. The regular consumption of meat likely enabled increases in brain size in the Homo lineage (Aiello and Wheeler 1995; Kaplan et al. 2000; Navarrete et al. 2011). Stone tools are associated with bone assemblages demonstrating early access to carcasses in the later Earlier Stone Age (Forrest 2017; Pickering et al. 2008; Smith et al. 2019). During the Middle Stone Age, H. sapiens routinely hunted large ungulates (Clark and Kandel 2013; Dusseldorp 2010; Faith 2008). Hunting is also the most knowledge-intensive foraging technique practised by contemporary foragers (Kaplan et al. 2000; Lombard 2015).

Middle Stone Age points are ubiquitous in many assemblages (and often produced using Levallois technology). Their dimensions regularly fit those of ethnographic spear points and points of atlatl darts (Brooks et al. 2006; Rots et al. 2011; Sahle et al. 2013; Sisk and Shea 2011). Some such points are fractured in ways suggesting hunting impact damage (Lombard 2005; Sahle et al. 2013; Wilkins et al. 2012; but see Rots and Plisson 2014). These suggestions are reinforced by the fact that the ability to throw accurately at high speeds evolved in encephalising hominins (Larson 2015; also see Gärdenfors and Lombard 2018 on spear hunting and cognition). The routine exploitation of mobile animal prey is reflected in other aspects of $H$. sapiens anatomy. Effective bipedal walking was likely present in the common ancestor of archaic H. sapiens and $H$. naledi. However, the development of endurance running, allowing ranging over 
large distances is only evident in H. sapiens. Ethnographically, hunting is associated with a far greater foraging range than plant exploitation (Binford 2001; Kelly 1983).

Increases in brain size also led to changes in social structure and cooperation (Boyd and Richerson 2009). As brains' energy consumption increased, provisioning became important - likely prior to the appearance of H. sapiens (Aiello and Key 2002; Kaplan, et al. 2000; Navarrete, et al. 2011). Because hunted meat comes in relatively large 'packages', the increased importance of hunting stimulates food sharing (also see Blurton Jones 1987; Jaeggi and Gurven 2013; Kaplan and Hill 1985), which in turn may have fostered increased cooperative behaviour and a division of labour (Aiello and Key 2002). In H. sapiens such a division of labour is universal (Kaplan, et al. 2000; Marlowe 2007). These changes may have also stimulated a social environment where effective teaching of tool production and other knowledge-intensive strategies played an increasing role ( $c f$. Gärdenfors and Högberg 2017).

Plant food exploitation was probably calorically more important than hunting (Dusseldorp 2014), and tool-assisted. Ethnographic analyses show that Kalahari hunter-gatherers largely rely on plant foods (Lee 1979; Wilmsen 1989). H. sapiens exploitation of plant foods likely also depended on the use of fire as a processing strategy (Larbey et al. 2019; Wadley et al. 2020). Fire control further allows for additional food storage strategies such as smoking and drying, and can play a role in social transmission by increasing time available for social interaction (Dunbar and Gowlett 2014). As the food supply in the Grassland Biome is unreliable, hominin populations need to develop strategies to deal with the challenges. Modern hunter-gatherers rely on long-term planning with food storage and food sharing (Dusseldorp 2014; Johnson 2014), and hunted meat is critical for dealing with food shortages in the dry season (Lee 1978). Technological investment in hafted Levallois-type stone tool technologies demonstrates that hunting was also a key component of the ecological niche of Middle Stone Age H. sapiens. We therefore argue that Pleistocene H. sapiens dealt with the Grassland Biome through a combination of knowledge-intensive food-gathering and hunting strategies. This type of 'foraging niche' requires considerable planning depth and cognitive astuteness, and tool use for a multitude of tasks is obligatory (Shea 2017).

\section{Homo naledi}

By the late Middle Pleistocene, the niches of $H$. naledi and $H$. sapiens diverged sufficiently for them to coexist in the same biome. This does not mean that the Grassland Biome represented the core of $H$. naledi's range. However, to successfully occupy it and be visible in the fossil record, it co-existed with large-bodied H. sapiens and also the chacma baboon (Papio ursinus), another generalist primate on the landscape (see Nel et al. in press). As $H$. naledi is one of the best represented hominin species anatomically, we can constrain its likely ecological niche. The anatomical indications for a lifeway combining efficient bipedal walking and habitual climbing activity suggest that $H$. naledi spent much time in different facets of the landscape than $H$. sapiens. Perhaps $H$. naledi existed mostly in a mosaic of grassland-forest environments with rocky outcrops and caves - such as the area surrounding the Cradle of Humankind today. This contrasts with the surrounding open grasslands, and those where Florisbad is located. Such a mosaic ecology could have provided a diverse range of plant, insect, and small animal food packages for exploitation. 
It is our contention that $H$. naledi was a habitual, but not an obligate tool user (Shea 2017). This is supported by their derived hand anatomy as well as by their evolutionary relationships within the genus Homo. The last common ancestor of H. naledi and its closest relatives (H. antecessor, $H$. heidelbergensis, $H$. sapiens, and Neanderthals) likely knapped stone tools (Dembo et al. 2016). The production and use of prepared core technology require depth of planning, communication, and deliberate social transmission, all of which remains to be established for $H$. naledi. However, relatively simple tools confer important fitness benefits on individuals, especially in the realm of plant exploitation. Pounding and shelling plant foods for example brings sizeable increases in foraging yield (Henry et al. 2014). Similarly, digging implements open up a rich variety of underground resources, whose consumption is supported by the chipping seen on $H$. naledi teeth.

In their analysis of $H$. naledi tooth wear, Berthaume et al. (2018) rightly caution that we should not revert to simplistic models, proposing an Australopithecus-like niche for Middle Pleistocene $H$. naledi. There are, however, functional anatomical similarities between australopithecines and $H$. naledi. The relatively small brain of $H$. naledi could mean that the knowledge-intensity of their foraging strategies was similar to those of australopithecines, even though the foraging strategies themselves may have differed. The dental evidence points to the consumption of underground storage organs with adhering sand grains and/or eating hard abrasive plant foods including nuts (Ungar et al. 2006; Ungar and Berger 2018). We have no reason to think that H. naledi could/ did not use anvils and hammerstones for cracking nuts. This techno-behaviour would have been well within the reach of the whole Homo lineage, both physically and cognitively (see Lombard et al. 2019).

$H$. naledi likely dealt with seasonal paucity in resource availability in a less knowledge-intensive way than $H$. sapiens. Food sharing was probably unimportant to $H$. naledi as this behaviour is associated with foods that come in large package sizes such as animal carcasses (Blurton Jones 1987). Also, as food storage requires a great degree of planning depth, we suggest this strategy was unimportant for H. naledi. As an alternative, we propose that $H$. naledi focused on relatively densely distributed resources, specifically extracted plant foods and perhaps insects and eggs. A reliance on plant underground storage organs literally opens up tonnes of food per hectare (Youngblood 2005) and is in line with their dental wear (Ungar and Berger 2018). We also think that $H$. naledi concentrated on grassland and forest mosaics within rocky outcrops on the greater Grassland Biome to buffer seasonal changes in food availability.

Likely living in smaller groups (Dunbar 1992), we think complex social mechanisms like teaching were limited in scope, and hence, transmission of elaborate behavioural strategies was restricted. Also, social learning mechanisms represent a form of cooperation that comes at a cost and is liable to exploitation by free-riders (Boyd and Richerson 2009; Hoppit et al. 2008). Instead, we propose the small-brained lineage likely evolved a reliance on simple transmission mechanisms and latent solutions (Tennie, et al. 2017), which could lead to the habitual use of tools, and to expedient ways of shaping them, such as grinding down the tips of digging implements or producing flakes with bipolar reduction. We therefore hypothesise that $H$. naledi occupied a niche focusing on the efficient exploitation of plant foods, insects, and probably small prey such as birds, lizards, rodents, etc. They likely relied on their fat 
reserves and on low-quality vegetable fallback foods to deal with uncertainty in food supply (Navarrete et al. 2011). In such a niche, the use of relatively simple, perhaps non-knapped tools, would result in important caloric and fitness benefits, differentiating their niches from both knowledge-intensive foraging by $H$. sapiens and the generalist, omnivore chacma baboon.

Currently, only a few archaeological occurrences are radiometrically dated to the temporal window occupied by the Dinaledi skeletal assemblage. Although no specific archaeological assemblages can be referred to it at this point, relatively simple stone artefacts are present in the late Middle Pleistocene archaeological record, especially in open-air occurrences on the Cradle of Humankind landscape such as Elandsdrift and Maropeng (Caruana 2017; Caruana et al. 2019; Moll 2017).

\section{Competition, Niche Differentiation, and Extinction}

The differentiating aspect of $H$. naledi and $H$. sapiens did not lie in the exploitation of plant foods per se. After all, H. sapiens also exploited plants (e.g. Henry et al. 2014; Larbey et al. 2019). Instead, we suggest there were three decisive differentiating factors:

1. H. sapiens concentrated on the more open facets of the landscape while H. naledi was likely present in more mosaic areas;

2. H. sapiens was able to greatly increase its meat intake as a fallback food ( $c f$. Lee 1978), while H. naledi likely was a hard-object fallback feeder (Ungar and Berger 2018);

3. H. sapiens employed multi-step processing including roasting to process starchy tubers (Larbey et al. 2019; Wadley et al. 2020), leading to increased efficiency of food exploitation on the grassland.

Differences in body size, energetic requirements, and anatomy ensured that the overlap between $H$. naledi's and $H$. sapiens' niches was small enough to enable successful coexistence. In our view it is unnecessary to invoke $H$. sapiens as a cause for the extinction of $H$. naledi. The latter has been cast as a remnant population (Spoor 2016), and in South Africa this may have been the case. The species was not primarily adapted to open grasslands that steadily expanded in South Africa's interior (Codron et al. 2008), leading to a decrease of suitable habitat for $H$. naledi in our model, and perhaps playing a role in its disappearance.

\section{Further Applications}

Our approach also works in cases of hominin co-existence with small anatomical differences such as Neanderthals and $H$. sapiens, hence applying to the transition between the Middle Palaeolithic and Upper Palaeolithic in Europe and the Near East. The assignation of different industries to either Neanderthals or H. sapiens is complex and in some cases still controversial (Bar-Yosef and Bordes 2010; Villa, et al. 2018; also see Lombard and Högberg 2021). Partly because of this, and partly due to taphonomic and dating problems, the process of Neanderthal extinction remains unclear. 
Earlier we showed that modelling on Neanderthal and H. sapiens co-existence often contains a built-in 'handicap' for Neanderthals, frequently based on assumed anatomical or behavioural differences. In a formalised model, this makes only one outcome possible. Nevertheless, recent reviews show that the known outcome (Neanderthal extinction) was potentially not the only possible outcome (Roebroeks and Soressi 2016; Villa and Roebroeks 2014, also see Langbroek 2012). Archaeological models should incorporate this. Some ingredients of a solution are available. Like $H$. naledi, Neanderthals are well-known anatomically. Some functional differences between Neanderthals and $H$. sapiens are known. Their lower limbs are shorter relative to H. Sapiens, impacting their cost of locomotion (Steudel-Numbers and Tilkens 2004). This likely had implications for their land-use strategies (MacDonald et al. 2009). Differences in land-use strategies are also suggested by analyses of raw material transports (Féblot-Augustins 1993; Roebroeks et al. 1988). Such land-use strategies have been interpreted to result in subtle differences in core reduction strategies in the Levant (Wallace and Shea 2006), so that in an area where typologically the products of $H$. sapiens and Neanderthals are indistinguishable from each other, an understanding of the ecological niche and the technological role therein may still allow differentiation of the archaeological remains of both populations.

Whereas the general shape of Homo brains is similar regardless of size, subtle variations are coming to light. For example, for at least one brain region-the precuneus - there exists evidence for recent, sapiens-exclusive expansion (Bruner 2010 ; 2021). Documented functions associated with the precuneus include visuospatial integration, category recognition, praxis, numerical processing, and speech decoding. What is more, the variation in morphological details of the region suggests neurofunctional differences in visuospatial integration. One potential behavioural consequence is variation in techno-behaviours such as the production and use of hunting weapons between the two species (Lombard and Högberg 2021). Although Neanderthals were capable of using ranged weapons (Milks et al. 2019), high-velocity projectile weapon systems such as bow-and-arrow sets, and perhaps also spearthrowers and darts, appear to be Middle to Late Pleistocene African developments by H. sapiens (Lombard 2020; Sahle and Brooks 2019).

Whereas variation in cognitive reasoning may have played a role in certain contexts between the species (Lombard and Högberg 2021), we propose that in the case of these large-brained hominins, contextual differences such as social structure, group size, and cultural dynamics must be included in any explanation for differences in their knapping strategies and tool-use. After all, both species were dependent on the production of mode 3 technologies for much of their existence (and modes 4 and 5 are not necessarily more cognitively challenging to knap). Both species were also capable of producing composite technology using adhesives to haft. This latter technology requires more than expert cognition, tapping into enhanced memory processes (Wynn et al. 2017). We thus argue that a better eye for subtle anatomical and technological differences, as well as cross-disciplinary approaches between two populations and the abandonment of teleological bias can lead to an improved understanding, also in this case. The anatomical differences in lower limb structure suggest Neanderthals exploited the landscape in a different way than $H$. sapiens. This combined with a different social system likely led to differing lithic adaptations. 


\section{Conclusion}

Archaeology as a discipline is still coming to terms with interpreting a record produced by multiple species on the same landscape. By taking on board anatomical and ecological evidence and combining it with a thorough understanding of the technological behaviours present in a region, it is possible to propose testable hypotheses for the behaviours of co-existing hominin populations. Understanding the association between techno-behaviours and hominins must be rooted within the context of the fitness benefits of these behaviours. This means abandoning gradualist and unilinear approaches. The discoveries of Neanderthal complexity and the discontinuous presence of so-called modern behaviours in the African archaeological record demonstrate that the development of complex behaviours is not a universal driving force of hominin behaviour. Complex behaviour is a situational phenomenon; its development and archaeological visibility depends on ecological and cultural circumstances (see Lombard and Högberg 2021).

The discovery and the surprisingly young age estimate of $H$. naledi bring into focus problems with the archaeological classification of stone tool assemblages. Most classificatory schemes mask the variability in the archaeological record and overestimate the requirements of the dominant blank production strategies. Based on the wellfounded assumption of niche differentiation and a review of the archaeological record, the fossil record, and $H$. naledi's anatomy, we developed a parsimonious, best-fit scenario to interpret the southern African record. We conclude that it is currently most prudent to think of $H$. naled $i$ as a habitual tool user, who possibly shaped implements. No stone tools are thus far associated with a $H$. naledi skeletal collection, which is insufficient reason to discount tool use altogether. Yet, we caution against a hasty assumption that they engaged in mode 3 tool production and use, simply because of their contemporaneity. Instead, anatomical arguments, among others a relatively small brain, suggest a different technological niche for $H$. naledi than for $H$. sapiens. It is our current understanding that $H$. naledi occupied mosaic areas in the landscape potentially exhibiting more climbing behaviour than large-brained hominins, and conclude that relatively simple tools, perhaps resulting from effective but cognitively undemanding mechanisms such as latent solutions, provided them with important fitness benefits. As such, their foraging niche relied on the tool-assisted exploitation of plant foods, and perhaps small prey (e.g. digging for insects). However, relatively minimal processing of these foods was practised, as reflected in their tooth wear.

We reconstruct the $H$. sapiens niche in the South African Middle Pleistocene as focused on open areas, and heavily technology assisted. They relied on well-developed expert and causal cognition for behavioural strategies, both in tool production, but also in knowledge-intensive foraging strategies. These included successful large mammal hunting and sharing of meat, especially as a fallback food. Their social relations also provided mechanisms to deal with temporary shortfalls in food and mechanisms aiding the transmission of complex behavioural strategies. Our reasoning is applicable to similar situations in the archaeological record, such as the study of the technological repertoire of early Plio-Pleistocene hominins with at times more than two sympatric hominin species (Wood and Boyle 2016), and also in cases of more closely-related populations such as the Neanderthals and H. sapiens in western Asia and Europe. Here, some form of competitive exclusion has often been assumed (Banks et al. 2008). 
Recent work emphasises the similarity of the knowledge-intensity of Neanderthal and H. sapiens behavioural strategies (Kolodny and Feldman 2017; Villa and Roebroeks 2014), whereas advances in palaeoneurology and studies in causal cognition highlight some variation between the two groups in terms of visuospatial integration and reasoning (Bruner 2010; Gärdenfors and Lombard 2018). In areas where their assemblages are not easily distinguished, such subtle anatomical differences may still provide ways to move forward. Further development could focus on more detailed studies, such as the examination of the spatial distribution of different technologies inside a specific region such as the Cradle of Humankind.

Acknowledgements Gerrit Dusseldorp is funded through NWO Vidi grant 276-60-004. Matt Caruana (University of Johannesburg) and Igor Djakovic (Leiden University) assisted with Fig. 2. We wish to thank three reviewers for their thoughtful and constructive comments.

\section{Compliance with Ethical Standards}

Conflict of Interest The authors declare that they have no conflict of interest.

Open Access This article is licensed under a Creative Commons Attribution 4.0 International License, which permits use, sharing, adaptation, distribution and reproduction in any medium or format, as long as you give appropriate credit to the original author(s) and the source, provide a link to the Creative Commons licence, and indicate if changes were made. The images or other third party material in this article are included in the article's Creative Commons licence, unless indicated otherwise in a credit line to the material. If material is not included in the article's Creative Commons licence and your intended use is not permitted by statutory regulation or exceeds the permitted use, you will need to obtain permission directly from the copyright holder. To view a copy of this licence, visit http://creativecommons.org/licenses/by/4.0/.

\section{References}

Adler, D. S., Wilkinson, K. N., Blockley, S., Mark, D. F., Pinhasi, R., Schmidt-Magee, B. A., et al. (2014). Early Levallois technology and the Lower to Middle Paleolithic transition in the Southern Caucasus. Science, 345(6204), 1609-1613.

Aiello, L., \& Wheeler, P. (1995). The expensive-tissue hypothesis, The brain and digestive system in human and primate evolution. Current Anthropology, 36(2), 199-221.

Aiello, L. C., \& Key, C. (2002). Energetic consequences of being a Homo erectus female. American Journal of Human Biology, 14(5), 551-565.

Akhilesh, K., Pappu, S., Rajapara, H. M., Gunnell, Y., Shukla, A. D., \& Singhvi, A. K. (2018). Early Middle Palaeolithic culture in India around 385-172 ka reframes out of Africa models. Nature, 554, 97.

Allen, T. F. H., Giampietro, M., \& Little, A. M. (2003). Distinguishing ecological engineering from environmental engineering. Ecological Engineering, 20(5), 389-407.

Aranguren, B., Revedin, A., Amico, N., Cavulli, F., Giachi, G., Grimaldi, S., et al. (2018). Wooden tools and fire technology in the early Neanderthal site of Poggetti Vecchi (Italy). Proceedings of the National Academy of Sciences, 115(9), 2054-2059.

Archer, W., Aldeias, V., McPherron, S.P. (2020). What is 'in situ'? A reply to Harmand et al. (2015). Journal of Human Evolution, 142, 102740.

Argue, D., Groves, C. P., Lee, M. Y. S., \& Jungers, W. L. (2017). The affinities of Homo floresiensis based on phylogenetic analyses of cranial, dental, and postcranial characters. Journal of Human Evolution, 107, $107-133$.

Backwell, L., \& d'Errico, F. (2008). Early hominid bone tools from Drimolen, South Africa. Journal of Archaeological Science, 35(11), 2880-2894. 
Banks, W. E., d'Errico, F., Peterson, A. T., Kageyama, M., Sima, A., \& Sánchez-Goñi, M. F. (2008). Neanderthal Extinction by Competitive Exclusion. PLoS One, 3(12), e3972.

Barham, L. (2013). From hand to handle: the first industrial revolution. Oxford: Oxford University Press.

Bar-Yosef, O., \& Bordes, J.-G. (2010). Who were the makers of the Châtelperronian culture? Journal of Human Evolution, 59(5), 586-593.

Barton, R. N. E., Bouzouggar, A., Collcutt, S. N., Carrión Marco, Y., Clark-Balzan, L., Debenham, N. C., \& Morales, J. (2016). Reconsidering the MSA to LSA transition at Taforalt Cave (Morocco) in the light of new multi-proxy dating evidence. Quaternary International, 413, 36-49.

Beaumont, P. B., \& Vogel, J. C. (2006). On a timescale for the past million years of human history in central South Africa. South African Journal of Science, 102(5-6), 217-228.

Benazzi, S., Bailey, S. E., Peresani, M., Mannino, M. A., Romandini, M., Richards, M. P., \& Hublin, J.-J. (2014). Middle Paleolithic and Uluzzian human remains from Fumane Cave, Italy. Journal of Human Evolution, 70, 61-68.

Berger, L. R., Hawks, J., de Ruiter, D. J., Churchill, S. E., Schmid, P., Delezene, L. K., et al. (2015). Homo naledi, a new species of the genus Homo from the Dinaledi Chamber, South Africa. eLife, 4, e09560.

Berger, L. R., Hawks, J., Dirks, P. H. G. M., Elliott, M., \& Roberts, E. M. (2017). Homo naledi and Pleistocene hominin evolution in subequatorial Africa. eLife, 6, e24234.

Berthaume, M. A., Delezene, L. K., \& Kupczik, K. (2018). Dental topography and the diet of Homo naledi. Journal of Human Evolution, 118, 14-26.

Beyene, Y., Katoh, S., WoldeGabriel, S., Hart, W. K., Uto, K., Sudo, M., et al. (2013). The characteristics and chronology of the earliest Acheulean at Konso, Ethiopia. Proceedings of the National Academy of Sciences, 110(5), 1584-1591.

Binford, L. R. (2001). Constructing frames of reference, An analytical method for archaeological theory building using ethnographic and environmental data sets. Berkeley/Los Angeles/London: University of California Press.

Blumenschine, R. J. (1987). Characteristics of an early hominid scavenging niche. Current Anthropology, 28(4), 383-407.

Blurton Jones, N. G. (1987). Tolerated theft, suggestions about the ecology and evolution of sharing, hoarding and scrounging. Information (International Social Science Council), 26(1), 31-54.

Boëda, E. (1988). Analyse technologique du débitage du niveau IIA. In Sommé, J., Tuffreau, A. (Eds.), Le gisement Paléolithique Moyen de Biache-Saint-Vaast (Pas-de-Calais) Volume I (pp. 185-214) Chalonssur-Marne: Chalons-sur-Marne.

Boyd, R., \& Richerson, P. J. (2009). Culture and the evolution of human cooperation. Philosophical Transactions of the Royal Society, B: Biological Sciences, 364, 3281-3288.

Bräuer, G. (2012). Middle Pleistocene diversity in Africa and the origin of modern humans. In J.-J. Hublin \& S. P. McPherron (Eds.), Modern origins: a North African perspective (pp. 221-240). Dordrecht: Springer.

Bräuer, G., \& Leakey, R. E. (1986). The ES-11693 cranium from Eliye Springs, West Turkana, Kenya. Journal of Human Evolution, 15(4), 289-312.

Bräuer, G., Groden, C., Gröning, F., Kroll, A., Kupczik, K., Mbua, E., et al. (2004). Virtual study of the endocranial morphology of the matrix-filled cranium from Eliye Springs, Kenya. The Anatomical Record Part A: Discoveries in Molecular, Cellular, and Evolutionary Biology, 276A(2), 113-133.

Brink, J. S. (2005). The evolution of the black wildebeest, Connochaetes gnou, and modern largemammal faunas in central Southern Africa. Stellenbosch: $\mathrm{PhD}$ Thesis University of Stellenbosch.

Brink, J. S. (2016). Faunal evidence for mid- and late Quaternary environmental change in South Africa. In J. Knight \& S. W. Grab (Eds.), Quaternary environmental change in southern Africa, Physical and human dimensions (pp. 284-305). Cambridge: Cambridge University Press.

Brooks, A. S., Nevell, L., Yellen, J. E., \& Hartman, G. (2006). Projectile Technologies of the African MSA. In E. Hovers \& S. L. Kuhn (Eds.), Transitions before the transition: evolution and stability in the Middle Paleolithic and Middle Stone Age (pp. 233-255). Boston: Springer.

Bruner, E. (2010). Morphological differences in the parietal lobes within the human genus: a neurofunctional perspective. Current Anthropology, 51(S1), S77-S88.

Bruner, E. (2021). Evolving human brains: paleoneurology and the fate of Middle Pleistocene. Journal of Archaeological Method and Theory. https://doi.org/10.1007/s10816-020-09500-8.

Bruner, E., \& Lombard, M. (2020). The skull from Florisbad: a paleoneurological report. Journal of Anthropological Sciences, 98, 89-97.

Caruana, M. V. (2017). Lithic production strategies in the Oldowan assemblages from Sterkfontein member 5 and Swartkrans member 1, Gauteng province, South Africa. Journal of African Archaeology, 15(1), 1-19. 
Caruana, M. V., Carvalho, S., Braun, D. R., Presnyakova, D., Haslam, M., Archer, W., et al. (2014). Quantifying traces of tool use: a novel morphometric analysis of damage patterns on percussive tools. PLoS One, 9(11), e113856.

Caruana, M. V., Tasker, D., \& Stratford, D. J. (2019). Identifying raw material transportation and reduction strategies from the lithic scatters at Elandsdrift Farm (Cradle of Humankind World Heritage Site), South Africa. African Archaeological Review, 36, 271-289.

Chazan, M. (2015). Technological Trends in the Acheulean of Wonderwerk Cave, South Africa. African Archaeological Review, 32(4), 701-728.

Churchill, S. E., Berger, L. R., \& Parkington, J. E. (2000). A Middle Pleistocene human tibia from Hoedjiespunt, Western Cape, South Africa. South African Journal of Science, 96(7), 367-368.

Clark, J. D. (1993). Stone artefact assemblages from members 1-3, Swartkrans Cave. In C. K. Brain (Ed.), A cave's chronicle of early man (pp. 167-194). Pretoria: Transvaal Museum.

Clark, J. G. D. (1969). World prehistory, a new outline. Cambridge: Cambridge University Press.

Clark, J. L., \& Kandel, A. W. (2013). The evolutionary implications of variation in human hunting strategies and diet breadth during the Middle Stone Age of southern Africa. Current Anthropology, 54(S8), S269S287.

Clarke, R. J. (1990). The Ndutu cranium and the origin of Homo sapiens. Journal of Human Evolution, 19(67), 699-736.

Clark, J. D., de Heinzelin, J., Schick, K. D., Hart, W. K., White, T. D., WoldeGabriel, G., Walter, R. C., Suwa, G., Asfaw, B., Vrba, E., \& Haile-Selassie, Y. (1994). African Homo erectus: old radiometric ages and young Oldowan assemblages in the Middle Awash Valley, Ethiopia. Science, 264(5167), 1907-1910.

Codron, D., Brink, J. S., Rossouw, L., \& Clauss, M. (2008). The evolution of ecological specialization in southern African ungulates: competition or physical environmental turnover. Oikos, 117(3), 344-353.

Cohen, P. (1996). Fitting a face to Ngaloba. Journal of Human Evolution, 30(4), 373-379.

Conroy, G. C., Weber, G. W., Seidler, H., Recheis, W., Zur Nedden, D., \& Mariam, J. H. (2000). Endocranial capacity of the Bodo cranium determined from three-dimensional computed tomography. American Journal of Physical Anthropology, 113(1), 111-118.

Corbey, R., Jagich, A., Vaesen, K., \& Collard, M. (2016). The Acheulean handaxe: more like a bird's song than a Beatles' tune? Evolutionary Anthropology, 25(1), 6-19.

Cortés-Sánchez, M., Jiménez-Espejo, F. J., Simón-Vallejo, M. D., Stringer, C., Lozano Francisco, M. C., García-Alix, A., et al. (2019). An early Aurignacian arrival in southwestern Europe. Nature Ecology and Evolution, 3(2), 207-212.

Cruz-Uribe, K., Klein, R. G., Avery, G., Avery, M., Halkett, D., Hart, T., et al. (2003). Excavation of buried Late Acheulean (Mid-Quaternary) land surfaces at Duinefontein 2, Western Cape Province, South Africa. Journal of Archaeological Science, 30(5), 559-575.

Davies, T. W., Delezene, L. K., Gunz, P., Hublin, J.-J., \& Skinner, M. (2019). Endostructural morphology in hominoid mandibular third premolars: discrete traits at the enamel-dentine junction. Journal of Human Evolution, 136, 102670.

DeCasien, A. R., Williams, S. A., \& Higham, J. P. (2017). Primate brain size is predicted by diet but not sociality. Nature Ecology and Evolution, 1, 0112.

De la Peña, P. (2019). Dating on its own cannot resolve hominin occupation patterns. Nature Ecology and Evolution, 3(5), 712-712.

Dembo, M., Radovcic, D., Garvin, H. M., Laird, M. F., Schroeder, L., Scott, J. E., et al. (2016). The evolutionary relationships and age of Homo naledi: an assessment using dated Bayesian phylogenetic methods. Journal of Human Evolution, 97, 17-26.

Diez-Martín, F., Sánchez Yustos, P., Uribelarrea, D., Baquedano, E., Mark, D.F., Mabulla, A., et al. (2015). The origin of the Acheulean: the 1.7 million-year-old site of FLK West, Olduvai Gorge (Tanzania). Scientific Reports, 5, 17839.

Dirks, P. H. G. M., Berger, L. R., Roberts, E. M., Kramers, J. D., Hawks, J., Randolph-Quinney, P. S., et al. (2015). Geological and taphonomic context for the new hominin species Homo naledi from the Dinaledi Chamber, South Africa. eLife, 4, e09561.

Dirks, P. H. G. M., Roberts, E. M., Hilbert-Wolf, H., Kramers, J. D., Hawks, J., Dosseto, A., et al. (2017). The age of Homo naledi and associated sediments in the Rising Star Cave, South Africa. eLife, 6, e24231.

Domínguez-Rodrigo, M., \& Alcalá, L. (2017). Pliocene archaeology at Lomekwi 3? New evidence fuels more skepticism. Journal of African Archaeology, 17(2), 173-176.

Dunbar, R. I. M. (1992). Neocortex size as a constraint on group size in primates. Journal of Human Evolution, 22(6), 469-493. 
Dunbar, R. I. M., \& Gowlett, J. A. J. (2014). Fireside chat: the impact of fire on hominin socioecology. In R. I. M. Dunbar, C. Gamble, \& J. A. J. Gowlett (Eds.), Lucy to language: the benchmark papers (pp. 277296). Oxford: Oxford University Press.

Dusseldorp, G. L. (2010). Prey choice during the South African Middle Stone Age: avoiding dangerous prey or maximising returns. African Archaeological Review, 27(2), 107-133.

Dusseldorp, G. L. (2014). Explaining the Howiesons Poort to post-Howiesons Poort transition: a review of demographic and foraging adaptation models. Azania, 49(3), 317-353.

Dusseldorp, G.L., Lombard, M., Wurz, S. (2013). Pleistocene Homo and the updated Stone Age sequence of South Africa. South African Journal of Science, 109(5/6), Art \#0042.

Egeland, C. P., Domínguez-Rodrigo, M., Pickering, T. R., Menter, C. G., \& Heaton, J. L. (2018). Hominin skeletal part abundances and claims of deliberate disposal of corpses in the Middle Pleistocene. Proceedings of the National Academy of Sciences, 115(18), 4601-4606.

Eren, M. I., \& Lycett, S. J. (2012). Why Levallois? A morphometric comparison of experimental 'preferential' Levallois flakes versus debitage flakes. PLoS One, 7(1), e29273.

Faisal, A., Stout, D., Apel, J., \& Bradley, B. (2010). The manipulative complexity of lower Paleolithic stone toolmaking. PLoS One, 5(11), e13718.

Faith, J. T. (2008). Eland, buffalo, and wild pigs: were Middle Stone Age humans ineffective hunters? Journal of Human Evolution, 55(1), 24-36.

Feathers, J. K. (2002). Luminescence dating in less than ideal conditions: case studies from Klasies River main site and Duinefontein, South Africa. Journal of Archaeological Science, 29(2), 177-194.

Féblot-Augustins, J. (1993). Mobility strategies in the Late Middle Palaeolithic of Central Europe and Western Europe: elements of stability and variability. Journal of Anthropological Archaeology, 12(3), 211-265.

Feuerriegel, E. M., Green, D. J., Walker, C. S., Schmid, P., Hawks, J., Berger, L. R., \& Churchill, S. E. (2017). The upper limb of Homo naledi. Journal of Human Evolution, 104, 155-173.

Foley, R. (1987). Another unique species, patterns in human evolutionary ecology. Harlow: Longman Scientific and Technical.

Foley, R., \& Gamble, C. (2009). The ecology of social transitions in human evolution. Philosophical Transactions of the Royal Society, B: Biological Sciences, 364(1533), 3267-3279.

Foley, R., \& Lahr, M. M. (2003). On stony ground: lithic technology, human evolution and the emergence of culture. Evolutionary Anthropology, 12(3), 109-122.

Forrest, F. (2017). Zooarchaeological and palaeoenvironmental reconstruction of newly excavated Middle Pleistocene deposits from Elandsfontein, South Africa. New York: PhD thesis City University of New York; 2017.

Galway-Witham, J., Cole, J., \& Stringer, C. (2019). Aspects of human physical and behavioural evolution during the last 1 million years. Journal of Quaternary Science, 34(6), 355-378.

Gärdenfors, P., \& Högberg, A. (2017). The archaeology of teaching and the evolution of Homo docens. Current Anthropology, 58(2), 188-208.

Gärdenfors, P., \& Lombard, M. (2018). Causal cognition, force dynamics and early hunting technologies. Frontiers in Psychology, 9, 87.

Gilpin, W., Feldman, M. W., \& Aoki, K. (2016). An ecocultural model predicts Neanderthal extinction through competition with modern humans. Proceedings of the National Academy of Sciences, 113(8), 2134-2139.

Goldfield, A. E., Booton, R., \& Marston, J. M. (2018). Modeling the role of fire and cooking in the competitive exclusion of Neanderthals. Journal of Human Evolution, 124, 91-104.

Gómez-Robles, A., Smaers, J. B., Holloway, R. L., Polly, P. D., \& Wood, B. A. (2017). Brain enlargement and dental reduction were not linked in hominin evolution. Proceedings of the National Academy of Sciences, 114(3), 468-473.

Goodwin, A. J. H., \& Van Riet Lowe, C. (1929). The Stone Age cultures of South Africa. Annals. South African Museum, 27, 1-289.

Gravina, B., Bachellerie, F., Caux, S., Discamps, E., Faivre, J.-P., Galland, A., et al. (2018). No reliable evidence for a Neanderthal-Châtelperronian association at La Roche-à-Pierrot, Saint-Césaire. Scientific Reports, 8(1), 15134.

Gravina, B., Mellars, P., \& Ramsey, C. B. (2005). Radiocarbon dating of interstratified Neanderthal and early modern human occupations at the Chatelperronian type-site. Nature, 438, 51-56.

Grine, F. E. (2000). Middle Stone Age human fossils from Die Kelders Cave 1, Western Cape Province, South Africa. Journal of Human Evolution, 38(1), 129-145.

Grine, F. E., \& Henshilwood, C. S. (2002). Additional human remains from Blombos Cave, South Africa: (1999-2000 excavations). Journal of Human Evolution, 42(3), 293-302. 
Grine, F. E., Marean, C. W., Faith, J. T., Black, W., Mongle, C. S., Trinkaus, E., Le Roux, S. G., \& Du Plessis, A. (2017). Further human fossils from the Middle Stone Age deposits of DieKelders Cave 1, Western Cape Province, South Africa. Journal of Human Evolution, 109, 70-78.

Grün, R., Brink, J. S., Spooner, N. A., Taylor, L., Stringer, C. B., Franciscus, R. G., \& Murray, A. S. (1996). Direct dating of Florisbad hominid. Nature, 382(6591), 500-501.

Grün, R., Beaumont, P., Tobias, P. V., \& Eggins, S. (2003). On the age of Border Cave 5 human mandible. Journal of Human Evolution, 45, 155-167.

Grün, R., Pike, A., McDermott, F., Eggins, S., Mortimer, G., Aubert, M., Kinsley, L., Joannes-Boyau, R., Rumsey, M., Denys, C., Brink, J., Clark, T., \& Stringer, C. (2020). Dating the skull from Broken Hill, Zambia, and its position in human evolution. Nature, 580, 372-375.

Haidle, M. N. (2010). Working-memory capacity and the evolution of modern cognitive potential: implications from animal and early human tool use. Current Anthropology, 51(S1), S149-S166.

Haidle, M. N., Bolus, M., Collard, M., Conard, N. J., Garofoli, D., Lombard, M., et al. (2015). The nature of culture: an eight-grade model for the evolution and expansion of cultural capacities in hominins and other animals. Journal of Anthropological Sciences, 93, 43-70.

Hallos, J. (2005). "15 Minutes of Fame": exploring the temporal dimension of Middle Pleistocene lithic technology. Journal of Human Evolution, 49(2), 155-179.

Hammer, M. F., Woerner, A. E., Mendez, F. L., Watkins, J. C., \& Wall, J. D. (2011). Genetic evidence for archaic admixture in Africa. Proceedings of the National Academy of Sciences, 108(37), 15123-15128.

Harcourt-Smith, W. E. H., Throckmorton, Z., Congdon, K. A., Zipfel, B., Deane, A. S., \& Drapeau, et al. (2015). The foot of Homo naledi. Nature Communications, 6, 8432.

Harmand, S., Lewis, J. E., Feibel, C. S., Lepre, C. J., Prat, S., Lenoble, A., et al. (2015). 3.3-million-year-old stone tools from Lomekwi 3, West Turkana, Kenya. Nature, 521(7552), 310-315.

Hawks, J., Berger, L. (2020). On Homo naledi and its significance in evolutionary anthropology. In DeaneDrummond, C., Fuentes, A. (Eds.) Theology and evolutionary anthropology: dialogues in wisdom, humility and grace (pp. pp.51-68), London: Routledge.

Hawks, J., Elliott, M., Schmid, P., Churchill, S. E., De Ruiter, D. J., Roberts, E. M., et al. (2017). New fossil remains of Homo naledi from the Lesedi Chamber, South Africa. eLife, 6, e24232.

Henry, A. G., Brooks, A. S., \& Piperno, D. R. (2014). Plant foods and the dietary ecology of Neanderthals and early modern humans. Journal of Human Evolution, 69, 44-54.

Herries, A. I. R. (2011). A chronological perspective on the acheulian and its transition to the Middle Stone Age in Southern Africa: the question of the Fauresmith. International Journal of Evolutionary Biology, $2011,25$.

Herzlinger, G., Wynn, T., \& Goren-Inbar, N. (2017). Expert cognition in the production sequence of Acheulian cleavers at Gesher Benot Ya'aqov, Israel: a lithic and cognitive analysis. PLoS One, 12(11), e0188337.

Higham, T., Douka, K., Wood, R., Ramsey, C. B., Brock, F., Basell, L., et al. (2014). The timing and spatiotemporal patterning of Neanderthal disappearance. Nature, 512, 306.

Hoffecker, J. F., \& Hoffecker, I. T. (2018). The structural and functional complexity of hunter-gatherer technology. Journal of Archaeological Method and Theory, 25(1), 202-225.

Holloway, R. L. (1981). Volumetric and asymmetry determinations on recent hominid endocasts: Spy I and II, Djebel Ihroud I, and the Salè Homo erectus specimens, with some notes on neandertal brain size. American Journal of Physical Anthropology, 55(3), 385-393.

Holloway, R. L. (1985). The poor brain of Homo neanderthalensis: see what you please. In E. Delson (Ed.), Ancestors: the hard evidence (pp. 319-324). New York: Alan R. Liss.

Holloway, R. L., Hurst, S. D., Garvin, H. M., Schoenemann, P. T., Vanti, W. B., Berger, L. R., \& Hawks, J. (2018). Endocast morphology of Homo naledi from the Dinaledi Chamber, South Africa. Proceedings of the National Academy of Sciences, 115(22), 5738-5743.

Hoppitt, W., Brown, G., Kendal, R., Rendell, L., Thornton, A., Webster, M., \& Laland, K. (2008). Lessons from animal teaching. Trends in Ecology \& Evolution, 23(9), 486-493.

Horan, R. D., Bulte, E., \& Shogren, J. F. (2005). How trade saved humanity from biological exclusion: an economic theory of Neanderthal extinction. Journal of Economic Behavior and Organization, 58(1), 129.

Hovers, E. (2012). Invention, Reinvention and Innovation: The Makings of Oldowan Lithic Technology. In S. Elias (Ed.), Origins of Human Innovation and Creativity (pp. 51-68). Amsterdam: Elsevier.

Hublin, J.-J., Ben-Ncer, A., Bailey, S. E., Freidline, S. E., Neubauer, S., Skinner, M. M., et al. (2017). New fossils from Jebel Irhoud, Morocco and the pan-African origin of Homo sapiens. Nature, 546(7657), 289292. 
Irish, J. D., Bailey, S. E., Guatelli-Steinberg, D., Delezene, L. K., \& Berger, L. R. (2018). Ancient teeth, phenetic affinities, and African hominins: another look at where Homo naledi fits in. Journal of Human Evolution, 122, 108-123.

Isaac, G. L. (1975). Sorting out the muddle in the middle: an anthropologist's post-conference appraisal. In K. W. Butzer \& G. L. Isaac (Eds.), After the Australopithecines: stratigraphy, ecology, and culture change in the Middle Pleistocene (pp. 875-887). The Hague, Paris: Mouton.

Isler, K., \& van Schaik, C. P. (2009). The expensive brain: a framework for explaining evolutionary changes in brain size. Journal of Human Evolution, 57(4), 392-400.

Jaeggi, A. V., \& Gurven, M. (2013). Reciprocity explains food sharing in humans and other primates independent of kin selection and tolerated scrounging: a phylogenetic meta-analysis. Proceedings of the Royal Society B: Biological Sciences, 280(1768), 20131615.

Johnson, A. L. (2014). Exploring adaptive variation among hunter-gatherers with Binford's frames of reference. Journal of Archaeological Research, 22(1), 1-42.

Joordens, J. C. A., d'Errico, F., Wesselingh, F. P., Munro, S., De Vos, J., Wallinga, J., et al. (2015). Homo erectus at Trinil on Java used shells for tool production and engraving. Nature, 518(7538), 228-231.

Kaplan, H., \& Hill, K. (1985). Food sharing among ache foragers: tests of explanatory hypotheses [and comments and reply]. Current Anthropology, 26(2), 223-246.

Kaplan, H., Hill, K., Lancaster, J., \& Hurtado, A. M. (2000). A theory of human life-history evolution: diet intelligence and longevity. Evolutionary Anthropology, 9(4), 156-185.

Kappelman, J. (1996). The evolution of body mass and relative brain size in fossil hominids. Journal of Human Evolution, 30(3), 243-276.

Kelly, R. L. (1983). Hunter-gatherer mobility strategies. Journal of Anthropological Research, 39(3), 277306.

Kempe, M., Lycett, S., \& Mesoudi, A. (2012). An experimental test of the accumulated copying error model of cultural mutation for Acheulean handaxe size. PLoS One, 7(11), e48333.

Key, A. J. M. (2016). Manual loading distribution during carrying behaviors: implications for the evolution of the hominin hand. PLoS One, 11(10), e0163801.

Kiberd, P. (2006). Bundu Farm: a report on archaeological and palaeoenvironmental assemblages from a pan site in Bushmanland, Northern Cape, South Africa. The South African Archaeological Bulletin, 61(184), 189-201.

Kivell, T. L., Deane, A. S., Tocheri, M. W., Orr, C. M., Schmid, P., Hawks, J., et al. (2015). The hand of Homo naledi. Nature Communications, 6, 8431.

Klein, R. G. (1973). Geological antiquity of Rhodesian man. Nature, 244, 311.

Klein, R. G. (2000). The earlier Stone Age of Southern Africa. The South African Archaeological Bulletin, 55(172), 107-122.

Klein, R. G., Avery, G., Cruz-Uribe, K., \& Steele, T. E. (2007). The mammalian fauna associated with an archaic hominin skullcap and later Acheulean artifacts at Elandsfontein, Western Cape Province, South Africa. Journal of Human Evolution, 52(2), 164-186.

Kolodny, O., \& Feldman, M. W. (2017). A parsimonious neutral model suggests Neanderthal replacement was determined by migration and random species drift. Nature Communications, 8(1), 1040.

Kozowyk, P. R. B., Langejans, G. H. J., \& Poulis, J. A. (2016). Lap shear and impact testing of ochre and beeswax in experimental Middle Stone Age compound adhesives. PLoS One, 11(3), e0150436.

Kuman, K., Inbar, M., \& Clarke, R. J. (1999). Palaeoenvironments and cultural sequence of the Florisbad Middle Stone Age hominid site, South Africa. Journal of Archaeological Science, 26(12), 1409-1425.

Lacruz, R. S., Brink, J. S., Hancox, P. J., Skinner, A. R., Herries, A., Schmid, P., \& Berger, L. R. (2002). Palaeontology and geological context of a Middle Pleistocene faunal assemblage from the Gladysvale Cave, South Africa. Palaeontologia Africana, 38, 99-114.

Langbroek, M. (2012). Trees and ladders: a critique of the theory of human cognitive and behavioural evolution in Palaeolithic archaeology. Quaternary International, 270, 4-14.

Larbey, C., Mentzer, S. M., Ligouis, B., Wurz, S., \& Jones, M. K. (2019). Cooked starchy food in hearths ca. 120 kya and 65 kya (MIS 5e and MIS 4) from Klasies River Cave, South Africa. Journal of Human Evolution, 131, 210-227.

Larson, S. G. (2015). Humeral torsion and throwing proficiency in early human evolution. Journal of Human Evolution, 85, 198-205.

Leakey, M. D. (1971). Olduvai Gorge: excavations in beds I and II, 1960-1963. Cambridge: Cambridge University Press.

Lee, R. B. (1978). Politics, sexual and non-sexual in an egalitarian society. Information (International Social Science Council), 17(6), 871-895. 
Lee, R. B. (1979). The !Kung San, Men women, and work in a foraging society. Cambridge: Cambridge University Press.

Lenoir, M., \& Villa, P. (2006). Hunting weapons of the Middle Stone Age and the Middle Palaeolithic: spear points from Sibudu, Rose Cottage and Bouheben. Southern African Humanities, 18(1), 89-122.

Leonard, W. R., Robertson, M. L., Snodgrass, J. J., \& Kuzawa, C. W. (2003). Metabolic correlates of hominid brain evolution. Comparative biochemistry and physiology Part A: Molecular and integrative physiology, $136(1), 5-15$.

Lepre, C. J., Roche, H., Kent, D. V., Harmand, S., Quinn, R. L., Brugal, J.-P., et al. (2011). An earlier origin for the Acheulian. Nature, 477(7362), 82-85.

Lewis, J. E., \& Harmand, S. (2016). An earlier date for stone tool making: implications for cognitive evolution and the transition to Homo. Philosophical Transactions of the Royal Society B, 371(1698), 20150233.

Li, H., Kuman, K., Lotter, M. G., Leader, G. M., \& Gibbon, R. J. (2017). The Victoria West: earliest prepared core technology in the Acheulean at Canteen Kopje and implications for the cognitive evolution of early hominids. Royal Society Open Science, 4(6).

Liebenberg, L. (2006). Persistence Hunting by Modern Hunter-Gatherers. Current Anthropology, 47(6), 1017-1026.

Lieberman, D. E., Bramble, D. M., Raichlen, D. A., \& Shea, J. J. (2007). The evolution of endurance running and the tyranny of ethnography: a reply to Pickering and Bunn (2007). Journal of Human Evolution, 53(4), 434-437.

Lombard, M. (2005). Evidence of hunting and hafting during the Middle Stone Age at Sibidu Cave, KwaZuluNatal, South Africa: a multianalytical approach. Journal of Human Evolution, 48(3), 279-300.

Lombard, M. (2015). Hunting and hunting technologies as proxy for teaching and learning during the stone age of Southern Africa. Cambridge Archaeological Journal, 25(4), 877-887.

Lombard, M. (2020). The tip cross-sectional areas of poisoned bone arrowheads from southern Africa. Journal of Archaeological Science: Reports, 33, 102477.

Lombard, M., \& Haidle, M. N. (2012). Thinking a bow-and-arrow set: cognitive implications of Middle Stone Age bow and stone-tipped arrow technology. Cambridge Archaeological Journal, 22(2), 237-264.

Lombard, M., \& Högberg, A. (2021). Four-field co-evolutionary model for human cognition: variation in the Middle Stone Age/Middle Palaeolithic. Journal of Archaeological Method and Theory. https://doi.org/10. 1007/s10816-020-09502-6.

Lombard, M., Högberg, A., \& Haidle, M. N. (2019). Cognition: from capuchin rock pounding to Lomekwian flake production. Cambridge Archaeological Journal, 29(2), 201-231.

Lombard, M., Jakobsson, M., \& Schlebusch, C. (2018). Ancient human DNA: how sequencing the genome of a boy from Ballito Bay changed human history. South African Journal of Science, 114(1/2), 1-3.

Lombard, M., Wadley, L., Deacon, J., Wurz, S., Parsons, I., Mohapi, M., et al. (2012). South African and Lesotho Stone Age sequence updated. South African Archaeological Bulletin, 67(195), 123-144.

Lotter, M. G. (2020a). A preliminary assessment of large cutting tool production at the Acheulean site of Penhill farm, lower Sundays River valley, Eastern Cape Province, South Africa. South African Archaeological Bulletin, 75(212), 58.

Lotter, M. G. (2020b). Stuck in a loop: investigating fabric patterns in the Stone Age gravel sequence at Canteen Kopje, Northern Cape Province, South Africa. Transactions of the Royal Society of South Africa, 75(1), 64-77.

Lotter, M. G., \& Kuman, K. (2017). The Acheulean in South Africa, with announcement of a new site (Penhill Farm) in the lower Sundays River Valley, Eastern Cape Province, South Africa. Quaternary International, 480, 43-65.

Lotter, M. G., Gibbon, R. J., Kuman, K., Leader, G. M., Forssman, T., \& Granger, D. E. (2016). A geoarchaeological study of the Middle and Upper Pleistocene levels at Canteen Kopje, Northern Cape Province, South Africa. Geoarchaeology, 31(4), 304-323.

Lycett, S. J., \& Gowlett, J. A. J. (2008). On questions surrounding the Acheulean 'tradition'. World Archaeology, 40(3), 295-315.

Lycett, S. J., Von Cramon-Taubadel, N., \& Gowlett, J. A. J. (2010). A comparative 3D geometric morphometric analysis of Victoria West cores: implications for the origins of Levallois technology. Journal of Archaeological Science, 37(5), 1110-1117.

MacDonald, K., Roebroeks, W., Verpoorte, A. (2009). An energetics perspective on the Neandertal record In Hublin, J.-J., Richards, M.P. (Eds.), The evolution of hominin diets, Integrating approaches to the study of Palaeolithic subsistence (pp. 211-220) Dordrecht: Springer.

Magori, C. C., \& Day, M. H. (1983). Laetoli Hominid 18: an early Homo sapiens skull. Journal of Human Evolution, 12(8), 747-753. 
Makhubela, T. V., Kramers, J. D., Scherler, D., Wittmann, H., Dirks, P. H. G. M., \& Winkler, S. R. (2019). Effects of long soil surface residence times on apparent cosmogenic nuclide denudation rates and burial ages in the Cradle of Humankind, South Africa. Earth Surface Processes and Landforms, 44(15), 29682981.

Manegold, A., \& Brink, J. S. (2011). Descriptions and palaeoecological implications of bird remainsfrom the Middle Pleistocene of Florisbad, South Africa. Paläontologische Zeitschrift, 85, 19-32.

Marchi, D., Walker, C. S., Wei, P., Holliday, T. W., Churchill, S. E., Berger, L. R., \& DeSilva, J. M. (2017). The thigh and leg of Homo naledi. Journal of Human Evolution, 104, 174-204.

Marean, C. W., Nilssen, P. J., Brown, K., Jerardino, A., \& Stynder, D. (2004). Palaeoanthropological investigations of Middle Stone Age sites at Pinnacle Point, Mossel Bay (South Africa): archaeology and hominid remains from the 2000 field season. Paleoanthropology, 2(1), 14-83.

Marlowe, F. W. (2007). Hunting and gathering: the human sexual division of foraging labor. Cross-Cultural Research, 41(2), 170-195.

Marzke, M. W. (2013). Tool making, hand morphology and fossil hominins. Philosophical Transactions of the Royal Society, B: Biological Sciences, 368(1630).

Mason, R. (1962). Prehistory of the Transvaal: a record of human activity. Johannesburg: Witwatersrand University Press.

McBrearty, S. (2005). The Kapthurin Formation: what we know now that we didn't know then. In D. E. Lieberman, R. J. Smith, \& J. Kelley (Eds.), Interpreting the past: essays on human, primate, and mammal evolution in honor of David Pilbeam (pp. 7-18). Boston: Brill Academic Publishers.

McBrearty, S., \& Brooks, A. S. (2000). The revolution that wasn't: a new interpretation of the origin of modern human behavior. Journal of Human Evolution, 39(5), 453-563.

McDougall, I., Brown, F. H., \& Fleagle, J. G. (2005). Stratigraphic placement and age of modern humans from Kibish, Ethiopia. Nature, 433, 733-736.

McPherron, S. P. (2000). Handaxes as a Measure of the Mental Capabilities of Early Hominids. Journal of Archaeological Science, 27(8), 655-663.

Meiring, A. J. D. (1956). The macrolithic culture of Florisbad. Researches of the National Museum, 1, 205.

Mercader, J., Patalano, R., Favreau, J., Itambu, M., Kumbani, J., \& Marufu, H. (2016). Acheulean prepared core technologies from the eastern Zimbabwe Escarpment, Maunganidze (Manicaland). Journal of Archaeological Science: Reports, 8, 47-62.

Milks, A., Parker, D., \& Pope, M. (2019). External ballistics of Pleistocene hand-thrown spears: experimental performance data and implications for human evolution. Scientific Reports, 9(1), 820.

Millard, A. R. (2006). Bayesian analysis of ESR dates, with application to Border Cave. Quaternary Geochronology, 1(2), 159-166.

Moll, R. M. (2017). A technological study of the lithic artefacts from the Earlier Stone Age site of Maropeng in the Craddle of Humankind, Gauteng, South Africa. Johannesburg: MSc thesis University of the Witwatersrand.

Montgomery, P. Q., Williams, H. O. L., Reading, N., \& Stringer, C. B. (1994). An assessment of the temporal bone lesions of the Broken Hill cranium. Journal of Archaeological Science, 21(3), 331-337.

Moore, M. W., \& Perston, Y. (2016). Experimental insights into the cognitive significance of early stone tools. PLoS One, 11(7), e0158803.

Morgan, T.J.H., Uomini, N.T., Rendell, L.E., Chouinard-Thuly, L., Street, S.E., Lewis, H.M., et al. (2015). Experimental evidence for the co-evolution of hominin tool-making, teaching and language. Nature Communications, 6, Article number 6029.

Morwood, M. J., Soejono, R. P., Roberts, R. G., Sutikna, T., Turney, C. S. M., Westaway, K. E., et al. (2004). Archaeology and age of a new hominin from Flores in eastern Indonesia. Nature, 431, 1087-1091.

Mucina, L., \& Rutherford, M. C. (2006). The vegetation of South Africa, Lesotho and Swaziland. Pretoria: National Botanical Institute.

Muller, A., Clarkson, C., \& Shipton, C. (2017). Measuring behavioural and cognitive complexity in lithic technology throughout human evolution. Journal of Anthropological Archaeology, 48, 166-180.

Navarrete, A., Van Schaik, C. P., \& Isler, K. (2011). Energetics and the evolution of human brain size. Nature, 480(7375), 91-93.

Nel, C., Bradfield, J., Lombard, L., Val, A. (in press). Taphonomic study of a modern baboon sleeping site at Misgrot, South Africa: implications for large-bodied primate taphonomy in karstic deposits. Journal of Paleolithic Archaeology.

Ogola, C.A. (2009). The Sterkfontein western breccias: statigraphy, fauna and artefacts. Johannesburg: $\mathrm{PhD}$ thesis, University of the Witwatersrand.

Osypiński, P., \& Osypińska, M. (2016). Optimal adjustment or cultural backwardness? New data on the latest Levallois industries in the Nile Valley. Quaternary International, 408, 90-105. 
Peringuey, L. (1911). The Stone Ages of South Africa as represented in the collection of the South African Museum. Annals. South African Museum, 8, 1-218.

Pickering, R., Hancox, P. J., Lee-Thorp, J. A., Grün, R., Mortimer, G. E., McCulloch, M., \& Berger, L. R. (2007). Stratigraphy, U-Th chronology, and paleoenvironments at Gladysvale Cave: insights into the climatic control of South African hominin-bearing cave deposits. Journal of Human Evolution, 53(5), 602-619.

Pickering, T. R., Egeland, C. P., Domínguez-Rodrigo, M., Brain, C. K., \& Schnell, A. G. (2008). Testing the "shift in the balance of power" hypothesis at Swartkrans, South Africa: hominid cave use and subsistence behavior in the Early Pleistocene. Journal of Anthropological Archaeology, 27(1), 30-45.

Pontzer, H., Brown, M. H., Raichlen, D. A., Dunsworth, H., Hare, B., Walker, K., et al. (2016). Metabolic acceleration and the evolution of human brain size and life history. Nature, 533, 390-392.

Pop, E., Charalampopoulos, D., Arps, C. S., Verbaas, A., Roebroeks, W., Gaudzinski-Windheuser, S., \& Langejans, G. (2018). Middle Palaeolithic percussive tools from the last interglacial site Neumark-Nord 2/ 2 (Germany) and the Visibility of Such Tools in the Archaeological Record. Journal of Paleolithic Archaeology, 1(2), 81-106.

Porat, N., Chazan, M., Grün, R., Aubert, M., Eisenmann, V., \& Horwitz, L. K. (2010). New radiometric ages for the Fauresmith industry from Kathu Pan, southern Africa: implications for the Earlier to Middle Stone Age transition. Journal of Archaeological Science, 37(2), 269-283.

Potts, R. (2011). Big brains explained. Nature, 480, 43-44.

Potts, R., Behrensmeyer, A. K., Deino, A., Ditchfield, P., \& Clark, J. (2004). Small mid-Pleistocene hominin associated with East African Acheulean technology. Science, 305(5680), 75-78.

Profitt, T., Luncz, L. V., Falótico, T., Ottoni, E. B., De la Torre, I., \& Haslam, M. (2016). Wild monkeys flake stone tools. Nature, 539, 85-88.

Putt, S. S., Wijeakumar, S., Franciscus, R. G., \& Spencer, J. P. (2017). The functional brain networks that underlie Early Stone Age tool manufacture. Nature Human Behaviour, 1, 0102.

Reynolds, S. C., \& Kibii, J. (2011). Sterkfontein at 75: review of paleoenvironments, fauna, dating and archaeology from the hominin site of Sterkfontein (Gauteng Province, South Africa). Palaeontologia Africana, 46, 59-88.

Reynolds, S. C., Clarke, R. J., \& Kuman, K. A. (2007). The view from the Lincoln Cave: mid- to late Pleistocene fossil deposits from Sterkfontein hominid site, South Africa. Journal of Human Evolution, 53(3), 260-271.

Richter, D., Grün, R., Joannes-Boyau, R., Steele, T. E., Amani, F., Rué, M., et al. (2017). The age of the hominin fossils from Jebel Irhoud, Morocco, and the origins of the Middle Stone Age. Nature, 546, 293.

Riga, A., Oxilia, G., Panetta, D., Salvadori, P., Benazzi, S., Wadley, L., \& Moggi-Cecchi, J. (2018). Human deciduous teeth from the Middle Stone Age layers of Sibudu Cave (South Africa). Journal of Anthropological Sciences, 96, 75.

Rightmire, G. P. (1978). Florisbad and human population succession in Southern Africa. American Journal of Physical Anthropology, 48(4), 475-486.

Rightmire, G. P. (2013). Homo erectus and Middle Pleistocene hominins: brain size, skull form, and species recognition. Journal of Human Evolution, 65(3), 223-252.

Roebroeks, W., \& Soressi, M. (2016). Neandertals revised. Proceedings of the National Academy of Sciences, $113(23), 6372-6379$.

Roebroeks, W., Kolen, J., \& Rensink, E. (1988). Planning depth, anticipation and the organization of MiddlePalaeolithic technology: the "archaic natives" meet Eve's descendants. Helinium, 28, 17-34.

Rots, V., \& Plisson, H. (2014). Projectiles and the abuse of the use-wear method in a search for impact. Journal of Archaeological Science, 48, 154-165.

Rots, V., Van Peer, P., \& Vermeersch, P. M. (2011). Aspects of tool production, use, and hafting in Palaeolithic assemblages from Northeast Africa. Journal of Human Evolution, 60(5), 637-664.

Ruebens, K., McPherron, S. J. P., \& Hublin, J.-J. (2015). On the local Mousterian origin of the Châtelperronian: integrating typo-technological, chronostratigraphic and contextual data. Journal of Human Evolution, 86, 55-91.

Sahle, Y., Brooks, A. S., \& Petraglia, M. D. (2019). Assessment of complex projectiles in the early Late Pleistocene at Aduma. Ethiopia. PLOS ONE, 14(5), e0216716.

Sahle, Y., Hutchings, W. K., Braun, D. R., Sealy, J. C., Morgan, L. E., Negash, A., \& Atnafu, B. (2013). Earliest stone-tipped projectiles from the Ethiopian Rift date to $>279,000$ years ago. PLoS One, 8(11), e78092.

Sampson, G. C. (1974). The Stone Age archaeology of Southern Africa. In New York. London: Academic Press. 
Scerri, E. M. L., Thomas, M. G., Manica, A., Gunz, P., Stock, J. T., Stringer, C., et al. (2018). Did our species evolve in subdivided populations across Africa, and why does it matter? Trends in Ecology \& Evolution, 33(8), 582-594.

Schlebusch, C. M., Malmström, H., Günther, T., Sjödin, P., Coutinho, A., Edlund, H., Munters, A. R., Vicente, M., Steyn, M., Soodyall, H., \& Lombard, M. (2017). Southern African ancient genomes estimate modern human divergence to 350,000 to 260,000 years ago. Science, 358(6363), 652-655.

Schlebusch, C. M., Sjödin, P., Breton, G., Günther, T., Naidoo, T., Hollfelder, N., Sjöstrand, A. E., Xu, J., Gattepaille, L. M., Vicente, M., Scofield, D. G., Malmström, H., De Jongh, M., Lombard, M., Soodyall, H., \& Jakobsson, M. (2020). Khoe-San genomes reveal unique variation and confirm the deepest population divergence in Homo sapiens. Molecular Biology and Evolution, Advance Access publication June, 12, 2020. https://doi.org/10.1093/molbev/msaa140.

Scherjon, F. (2019). Virtual Neanderthals : a study in agent-based modelling Late Pleistocene hominins in western Europe. PhD-thesis: Leiden University.

Schwartz, J. H., \& Tattersall, I. (2003). The human fossil record Volume two: Craniodental morphology of genus Homo (Africa and Asia). Hoboken: Wiley-Liss.

Scott, L., Van Aardt, A. C., Brink, J. S., Toffolo, M. B., Ochando, J., \& Carrión, J. S. (2019). Palynology of Middle Stone Age spring deposits in grassland at the Florisbad hominin site, South Africa. Review of Palaeobotany and Palynology, 265, 13-26.

Shea, J. J. (2003). Neandertals, competition and the origin of modern human behaviour in the Levant. Evolutionary Anthropology, 12(4), 173-187.

Shea, J. J. (2011). Homo sapiens is as Homo sapiens was. Current Anthropology, 52(1), 1-35.

Shea, J. J. (2013). Lithic modes A-I: a new framework for describing global-scale variation in stone tool technology illustrated with evidence from the East Mediterranean Levant. Journal of Archaeological Method and Theory, 20(1), 151-186.

Shea, J. J. (2017). Occasional, obligatory, and habitual stone tool use in hominin evolution. Evolutionary Anthropology, 26(5), 200-217.

Shipton, C. (2018). Biface knapping skill in the East African Acheulean: progressive trends and random walks. African Archaeological Review, 35(1), 107-131.

Singer, R. (1954). The Saldanha skull from Hopefield, South Africa. American Journal of Physical Anthropology, 12(3), 345-362.

Sisk, M. L., \& Shea, J. J. (2011). The African origin of complex projectile technology: an analysis using tip cross-sectional area and perimeter. International Journal of Evolutionary Biology, 2011, 8.

Smith, G. M., Ruebens, K., Gaudzinski-Windheuser, S., \& Steele, T. E. (2019). Subsistence strategies throughout the African Middle Pleistocene: faunal evidence for behavioral change and continuity across the Earlier to Middle Stone Age transition. Journal of Human Evolution, 127, 1-20.

Spoor, C. F. (2016). Evolving primates: a palaeontologist's view of his tribe. Amsterdam: ACASA dept. of Archaeology, University of Amsterdam.

Spoor, F., Gunz, P., Neubauer, S., Stelzer, S., Scott, N., Kweakason, A., \& Dean, M. C. (2015). Reconstructed Homo habilis type $\mathrm{OH} 7$ suggests deep-rooted species diversity in early Homo. Nature, 519, 83-86.

Stammers, R. C., Caruana, M. V., \& Herries, A. I. R. (2018). The first bone tools from Kromdraai and stone tools from Drimolen, and the place of bone tools in the South African Earlier Stone Age. Quaternary International, 495, 87-101.

Steudel-Numbers, K. L., \& Tilkens, M. J. (2004). The effect of lower limb length on the energetic cost of locomotion: implications for fossil hominins. Journal of Human Evolution, 47(1-2), 95-109.

Stout, D., \& Khreisheh, N. (2015). Skill learning and human brain evolution: an experimental approach. Cambridge Archaeological Journal, 25(4), 867-875.

Stout, D., Apel, J., Commander, J., \& Roberts, M. (2014). Late Acheulean technology and cognition at Boxgrove, UK. Journal of Archaeological Science, 41, 576-590.

Stout, D., Rogers, M. J., Jaeggi, A. V., \& Semaw, S. (2019). Archaeology and the origins of human cumulative culture: a case study from the earliest Oldowan at Gona, Ethiopia. Current Anthropology, 60(3), 309-340.

Stynder, D. D., Moggi-Cecchi, J., Berger, L. R., \& Parkington, J. E. (2001). Human mandibular incisors from the late Middle Pleistocene locality of Hoedjiespunt 1, South Africa. Journal of Human Evolution, 41(5), 369-383.

Susman, R. L. (1994). Fossil evidence for early hominid tool use. Science, 265(5178), 1570-1573.

Szabo, B. J., \& Butzer, K. W. (1979). Uranium-series dating of lacustrine limestones from pan deposits with final Acheulian assemblage at Rooidam, Kimberley District, South Africa. Quaternary Research, 11(2), $257-260$. 
Tennie, C., Braun, D. R., Premo, L. S., \& McPherron, S. P. (2016). The island test for cumulative culture in the Paleolithic. In M. N. Haidle, N. J. Conard, \& M. Bolus (Eds.), The nature of culture: based on an interdisciplinary symposium 'the nature of culture', Tübingen, Germany (pp. 121-133). Dordrecht: Springer.

Tennie, C., Premo, L. S., Braun, D. S., \& McPherron, S. (2017). Early stone tools and cultural transmission: resetting the null hypothesis. Current Anthropology, 58(5), 652-672.

Terry, H. (2005). The Namibia Palaeolithic field research project (Nampal) 2002. The South African Archaeological Bulletin, 60(181), 20-23.

Thompson, E., Williams, H. M., \& Minichillo, T. (2010). Middle and late Pleistocene Middle Stone Age lithic technology from Pinnacle Point 13B (Mossel Bay, Western Cape Province, South Africa). Journal of Human Evolution, 59(3-4), 358-377.

Tryon, C. A., McBrearty, S., \& Texier, P.-J. (2005). Levallois lithic technology from the Kapthurin Formation, Kenya: Acheulian origin and Middle Stone Age diversity. African Archaeological Review, 22, 199-229.

Tobias, P. V. (1971). Human skeletal remains from the cave of Hearths, Makapansgat, Northern Transvaal. American Journal of Physical Anthropology, 34(3), 335-367.

Tocheri, M. W., Orr, C. M., Jacofsky, M. C., \& Marzke, M. W. (2008). The evolutionary history of the hominin hand since the last common ancestor of Pan and Homo. Journal of Anatomy, 212(4), 544-562.

Toth, N., \& Schick, K. (2018). An overview of the cognitive implications of the Oldowan Industrial Complex. Azania: Archaeological Research in Africa, 53(1), 3-39.

Towle, I., Irish, J. D., \& De Groote, I. (2017). Behavioral inferences from the high levels of dental chipping in Homo naledi. American Journal of Physical Anthropology, 164(1), 184-192.

Ungar, P. S., \& Berger, L. R. (2018). Dental microwear and diet of Homo naledi. American Journal of Physical Anthropology, 166(1), 228-235.

Ungar, P. S., Grine, F. E., Teaford, M. F., \& El Zaatari, S. (2006). Dental microwear and diets of African early Homo. Journal of Human Evolution, 50(1), 78-95.

Uomini, N. T., \& Meyer, G. F. (2013). Shared brain lateralization patterns in language and Acheulean stone tool production: a functional transcranial Doppler ultrasound study. PLoS One, 8(8), e72693.

Vaesen, K., \& Houkes, W. (2018). Complexity and technological evolution: what everybody knows? Biology and Philosophy, 32(6), 1245-1268.

Vaesen, K., Scherjon, F., Hemerik, L., Verpoorte, A., \& Lozano, S. (2019). Inbreeding, Allee effects and stochasticity might be sufficient to account for Neanderthal extinction. PLOS ONE, 14(11), e0225117.

Val, A. (2016). Deliberate body disposal by hominins in the Dinaledi Chamber, Cradle of Humankind, South Africa? Journal of Human Evolution, 96, 145-148.

Verna, C., Texier, P. J., Rigaud, J. P., Poggenpoel, C., \& Parkington, J. (2013). The middle stone age human remains from Diepkloof rock shelter (Western Cape, South Africa). Journal of Archaeological Science, 40(9), 3532-3541.

Villa, P., Pollarolo, L., Conforti, J., Marra, F., Biagioni, C., Degano, I., et al. (2018). From Neandertals to modern humans: new data on the Uluzzian. PLoS One, 13(5), e0196786.

Villa, P., \& Roebroeks, W. (2014). Neandertal demise: an archaeological analysis of the modern human superiority complex. PLoS One, 9(4), e96424.

Volman, T. P. (1981). The Middle Stone Age in the southern Cape. Chicago: PhD-thesis, University of Chicago.

Wadley, L. (2015). Those marvellous millennia: the Middle Stone Age of southern Africa. Azania, 50(2), $155-226$.

Wadley, L., Backwell, L., d'Errico, F., \& Sievers, C. (2020). Cooked starchy rhizomes in Africa 170 thousand years ago. Science, 367(6473), 87-91.

Wadley, L., Hodgskiss, T., \& Grant, M. (2009). Implications for complex cognition from the hafting of tools with compound adhesives in the Middle Stone Age, South Africa. Proceedings of the National Academy of Sciences, 106(24), 9590-9594.

Wallace, I. J., \& Shea, J. J. (2006). Mobility patterns and core technologies in the Middle Paleolithic of the Levant. Journal of Archaeological Science, 33(9), 1293-1309.

Wallace, I. J., Burgess, M. L., \& Patel, B. A. (2020). Phalangeal curvature in a chimpanzee raised like a human: implications for inferring arboreality in fossil hominins. Proceedings of the National Academy of Sciences, 117(21), 11223-11225.

Weiss, M., Lauer, T., Wimmer, R., \& Pop, C. M. (2018). The variability of the Keilmesser-concept: a case study from Central Germany. Journal of Paleolithic Archaeology, 1(3), 202-246.

Wenban-Smith, F. F., Allen, P., Bates, M. R., Parfitt, S. A., Preece, R. C., Stewart, J. R., et al. (2006). The Clactonian elephant butchery site at Southfleet Road, Ebbsfield, UK. Journal of Quaternary Science, 21(5), 471-483. 
White, M. J. (2000). The Clactonian question: on the interpretation of core-and-flake assemblages in the British Lower Paleolithic. Journal of World Prehistory, 14(1), 1-63.

White, T. D., Asfaw, B., DeGusta, D., Gilbert, H., Richards, G. D., Suwa, G., \& Howell, F. C. (2003). Pleistocene Homo sapiens from Middle Awash, Ethiopia. Nature, 423, 742-747.

Wiersma, J. P., Roberts, E. M., \& Dirks, P. H. G. M. (2020). Formation of mud clast breccias and the processof sedimentary autobrecciation in the hominin-bearing(Homo naledi) Rising Star Cave system, South Africa. Sedimentology, 67(2), 897-919.

Wilkins, J., Pollarolo, L., \& Kuman, K. (2010). Prepared core reduction at the site of Kudu Koppie in northern South Africa: temporal patterns across the Earlier and Middle Stone Age boundary. Journal of Archaeological Science, 37(6), 1279-1292.

Wilkins, J., Schoville, B. J., Brown, K. S., \& Chazan, M. (2012). Evidence for Early Hafted Hunting Technology. Science, 338(6109), 942-946.

Will, M., Pablos, A., \& Stock, J. T. (2017). Long-term patterns of body mass and stature evolution within the hominin lineage. Royal Society Open Science, 4(11).

Will, M., El-Zataari, S., Harvati, K., \& Conard, N. J. (2019). Human teeth from securely stratified Middle Stone Age contexts at Sibudu, South Africa. Archaeological and Anthropological Sciences, 11, 34913501 .

Williams, S. (2017). Australopithecus Group. In T. K. Shackelford \& V. A. Weekes-Shackelford (Eds.), Encyclopedia of Evolutionary Psychological Science (pp. 1-7). Dordrecht: Springer.

Williams, E. M., Gordon, A. D., \& Richmond, B. G. (2010). Upper limb kinematics and the role of the wrist during stone tool production. American Journal of Physical Anthropology, 143(1), 134-145.

Williams, E. M., Gordon, A. D., \& Richmond, B. G. (2014). Biomechanical strategies for accuracy and force generation during stone tool production. Journal of Human Evolution, 72, 52-63.

Williams, S. A., García-Martínez, D., Bastir, M., Meyer, M. R., Nalla, S., \& Hawks, et al. (2017). The vertebrae and ribs of Homo naledi. Journal of Human Evolution, 104, 136-154.

Wilmsen, E. N. (1989). Land filled with flies: a political economy of the Kalahari. Chicago: Chicago University Press.

Wood, B. (2011). Wiley-Blackwell Encyclopedia of human evolution. Oxford: Wiley-Blackwell.

Wood, B. M. (2014). Fifty years after Homo habilis. Nature, 508, 31-33.

Wood, B., \& Boyle, E. K. (2016). Hominin taxic diversity: fact or fantasy? American Journal of Physical Anthropology, 159(S61), 37-78.

Wynn, T., Coolidge, F.L. (2011). The Implications of the Working Memory Model for the Evolution of Modern Cognition. International Journal of Evolutionary Biology, 2011.

Wynn, T., Haidle, M. N., Lombard, M., \& Coolidge, F. L. (2017). The expert cognition model in human evolutionary studies. In T. Wynn \& F. L. Coolidge (Eds.), Cognitive models in archaeology (pp. 21-43). Oxford: Oxford University Press.

Youngblood, D. (2005). Identifications and quantification of edible plant foods in the Upper (Nama) Karoo, South Africa. Economic Botany, 58(Suppl 1), S43.

Zilhão, J., d'Errico, F., Bordes, J.-G., Lenoble, A., Texier, J.-P., \& Rigaud, J.-P. (2006). Analysis of Aurignacian interstratification at the Châtelperronian-type site and implications for the behavioral modernity of Neandertals. Proceedings of the National Academy of Sciences, 103(33), 12643-12648.

Zubrow, E. (1989). The demographic modelling of Neanderthal extinction. In P. Mellars \& C. B. Stringer (Eds.), The human revolution: behavioural and biological perspectives on the origins of modern humans (pp. 212-231). Edinburgh: Edingburgh University Press.

Publisher's Note Springer Nature remains neutral with regard to jurisdictional claims in published maps and institutional affiliations. 